\title{
Composição, estrutura e similaridade florística da Floresta Atlântica, na Serra Negra, Rio Preto - MG
} Composition, structure and floristic similarity of Atlantic Forest, Serra Negra, Rio Preto - MG

\author{
Arthur Sérgio Mouço Valente ${ }^{1,3}$, Paulo Oswaldo Garcia ${ }^{1}$, \\ Fátima Regina Gonçalves Salimena ${ }^{1} \&$ Ary Teixeira de Oliveira-Filho ${ }^{2}$
}

\begin{abstract}
Resumo
A Serra Negra, no município de Rio Preto (MG), estende-se por uma região com fisionomias florestais serranas da Mantiqueira e campos altimontanos, entre as elevações do maciço do Itatiaia (RJ, SP e MG) e da Serra do Ibitipoca (MG). Com o objetivo de investigar o comportamento das variáveis comunitárias da flora arbórea em condições diferentes de altitude e alagamento, determinou-se a composição florística, estrutura e similaridade entre três fragmentos de floresta (aluvial, montana e nebular) e a suas relações florísticas com estudos da região. Foram amostrados 2.572 indivíduos, identificados em 194 espécies, distribuídas em 59 famílias e 118 gêneros. As famílias com maior riqueza foram Myrtaceae (30 espécies), Lauraceae (20), Melastomataceae (17) e Fabaceae (13). Os três tipos de vegetação estudados, associados a diferentes condições ambientais, diferem entre si em sua composição e estrutura. A floresta aluvial revelou-se com reduzida diversidade, baixa estatura e alta dominância ecológica. A floresta nebular destacou-se por apresentar elementos típicos de altitude em detrimento de espécies freqüentes na região abaixo da escarpa da serra, onde a diversidade foi maior. A flora arbórea da Serra Negra, formada pelo conjunto das áreas estudadas, apresenta um conjunto considerável de elementos com distribuição característica de ambientes montanhosos do Sudeste do Brasil.
\end{abstract}

Palavras-chave: ecologia de comunidades, flora arbórea, gradiente de altitude, floresta nebular, floresta ombrófila aluvial.

\begin{abstract}
Serra Negra is a region surrounded by some stretches of mountain, covered by Atlantic Forests and cloud scrubs, located in the southern part of Zona da Mata of Minas Gerais, in Serra da Mantiqueira, between the rises of the massif of Itatiaia (RJ, SP e MG) and the Serra do Ibitipoca (MG). The aim of this study was to determine the composition, structure and floristic similarity of arboreal flora among three forest types of Atlantic Forest (Alluvial, Montane and Cloud Forest) and also the similarity with other studies. A total of 2,572 individuals was sampled, from 194 species, 59 families and 118 genera. The highest number of species was recorded in the families Myrtaceae (30 morphospecies), Lauraceae (20), Melastomataceae (17) and Fabaceae (13). The three vegetation types associated with different environmental conditions differ in their composition and structure. The alluvial proved with low diversity and stature and high ecological dominance. The cloud forest stood out for its typical elements of altitude over other common species in the area below the range, where diversity was higher. The tree flora of Sierra Negra presents various indicator species to characteristic distribution of highlands of southeastern Brazil.
\end{abstract}

Key words: community ecology, tree flora, altitudinal gradient, cloud forest, alluvial forest.

\section{Introdução}

A Mata Atlântica mineira é a maior área do bioma numa unidade da Federação, mesmo sem considerar disjunções nos outros domínios do estado, o que evidencia a responsabilidade deste na conservação do bioma (Meira-Neto
2006). Na Zona da Mata mineira, cinco formações da Floresta Atlântica são encontradas, sendo elas as florestas ombrófilas baixo-montana e altomontana e as florestas estacionais semideciduais submontana, baixo-montana e alto-montana (Valente et al.2006). Essas formam um conjunto de

\footnotetext{
${ }^{1}$ Programa de Pós-Graduação em Ecologia. Universidade Federal de Juiz de Fora, Instituto de Ciências Biológicas, 36036-330, Juiz de Fora, MG, Brasil.

${ }^{2}$ Universidade Federal de Minas Gerais, Depto. Botânica, 31270-901, Belo Horizonte, MG, Brasil.

${ }^{3}$ Autor para correspondência: artvalente@yahoo.com.br
} 
ecossistemas da Floresta Atlântica, inseridos no grande domínio dos "mares de morros", na porção sul-oriental de Minas Gerais.

O nível de interiorização da Mata Atlântica em Minas Gerais e interior fluminense perfaz de 500 a $600 \mathrm{~km}$, comportando sempre florestas tropicais de planaltos, dotados de clima mesotérmico, com $18^{\circ}$ a $20^{\circ} \mathrm{C}$ de temperatura e 1.300 a $1.600 \mathrm{~mm}$ de precipitações anuais (Ab’Sáber 2003). Reiteram-se os fortes acréscimos de chuvas e nevoeiros na fachada atlântica das serras do Mar e da Mantiqueira (Ab'Saber 2003).

Naturalmente, devido à ampla extensão territorial de Minas Gerais, ocorrem diferenciações florísticas com as variações espaciais, como as de latitude e grau de interiorização (Oliveira-Filho \& Fontes 2000). Porém, em menor escala, a heterogeneidade fitofisionômica e florística apresenta intríseca relação com a heterogeneidade ambiental local (Durigan et al. 2000; Pereira et al. 2007). Estas peculiariedades e/ou dissimilaridades estruturais e de composição podem ser decorrentes da altitude (Pendry \& Proctor 1996), de propriedades do solo (Oliveira-Filho et al. 1994; Torres et al. 1997; Dalanesi et al. 2004; Carvalho et al. 2005) e do nível de encharcarmento do substrato (Rodrigues \& Leitão Filho 2004). Outros fatores associados à altitude foram estudados como causas diretas dessas variações (Damasceno-Júnior 2005), como a diminuição da temperatura mínima e aumento da nebulosidade. Em florestas tropicais, as diferenças florísticas ao longo do gradiente de altitude ocorrem com mudanças na estrutura (Lieberman et al. 1996; Whitmore 1998; Meireles et al.2008) e na riqueza e diversidade de famílias e espécies, padrões já bem detalhados para as florestas andinas (Gentry 1995) e brasileiras (Rodrigues 1989; Guedes 1998; OliveiraFilho \& Fontes 2000; Sanchez 2001; Meireles et al. 2008). A caracterização das florestas de altitude e suas relações florísticas tornam-se importantes, pois permitem a compreensão dos padrões de diferenciação florística existentes nas serras da costa atlântica (Oliveira-Filho et al. 2005; Soares et al.2006; Pereira et al.2006).

A serra da Mantiqueira abrange parte dos estados de São Paulo, Rio de Janeiro, Minas Gerais eEspírito Santo. Em Minas Gerais, encontram-se neste complexo serrano cerca de $20 \%$ dos remanescentes da Mata Atlântica, bioma reduzido a pouco mais de $4 \%$ de sua cobertura original no estado (Costa \& Herrmann 2006). A Serra Negra, componente do complexo da Mantiqueira, está incluída na região denominada Bom Jardim, com alta prioridade para a conservação da flora de Minas Gerais, sendo recomendada a investigação científica em forma de inventários, devido à alta diversidade e ao baixo conhecimento científico da área (Drummond et al. 2005). Desta forma, este estudo contribui pioneiramente para o conhecimento das comunidades florestais dessa área.

O presente estudo desenvolveu-se em três fragmentos de tipos florestais distintos na Serra Negra, MG, com os objetivos de descrever, para cada área, a composição e diversidade florística do estrato arbóreo, bem como sua estrutura horizontal e vertical; e comparar a similaridade entre os três fragmentos e destes com outros estudos na Serra da Mantiqueira.

\section{Material e Métodos}

\section{Área de estudo}

$\mathrm{O}$ estudo foi realizado na região da Serra Negra, que compõe a microbacia do Ribeirão do Funil, situada no município de Rio Preto (22 $05^{\circ} \mathrm{S}$ e $43^{\circ} 49^{\prime} \mathrm{W}$ ), na região sul da Zona da Mata mineira (Fig. 1). Esta serra, cuja altitude máxima está a $1.698 \mathrm{~m}$, é uma elevação de rochas quartzíticas semelhantes às da Serra do Ibitipoca, da qual dista cerca de $20 \mathrm{~km}$ em linha reta ao norte. A paisagem constitui um mosaico de florestas e campos rupestres, cujas características são pouco estudadas. O clima é do tipo Cwb, segundo classificação de Köppen (Peel et al. 2007), mesotérmico úmido, com invernos secos e frios e verões brandos e úmidos. A média da precipitação anual, entre 1946 e 2004, foi de $1.886 \mathrm{~mm}$ e mediana de $1.902 \mathrm{~mm}$ segundo dados da Prefeitura Municipal de Rio Preto, Estação Metereológica da vila do Funil.

\section{Caracterização dos fragmentos}

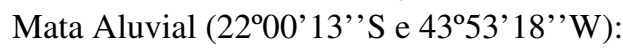
fragmento de 9,2 ha, a cerca de $900 \mathrm{~m}$ de altitude. Compreende um trecho de embaciamento, periodicamente inundado pela elevação do nível freático, com microrrelevo composto de murundus e depressões. O substrato é argiloso (Tab. 1) com drenagem muito pobre. É conhecida localmente por Mata de Cambuí, uma referência ao nome popular da espécie Myrciaria tenella (DC.) O.Berg, que predomina nesta área. A formação classifica-se como floresta ombrófila densa aluvial, de acordo com Veloso et al. (1991), e floresta latifoliada pluvial perenifólia tropical inferomontana inundável, de acordo com Oliveira-Filho (2009a). 

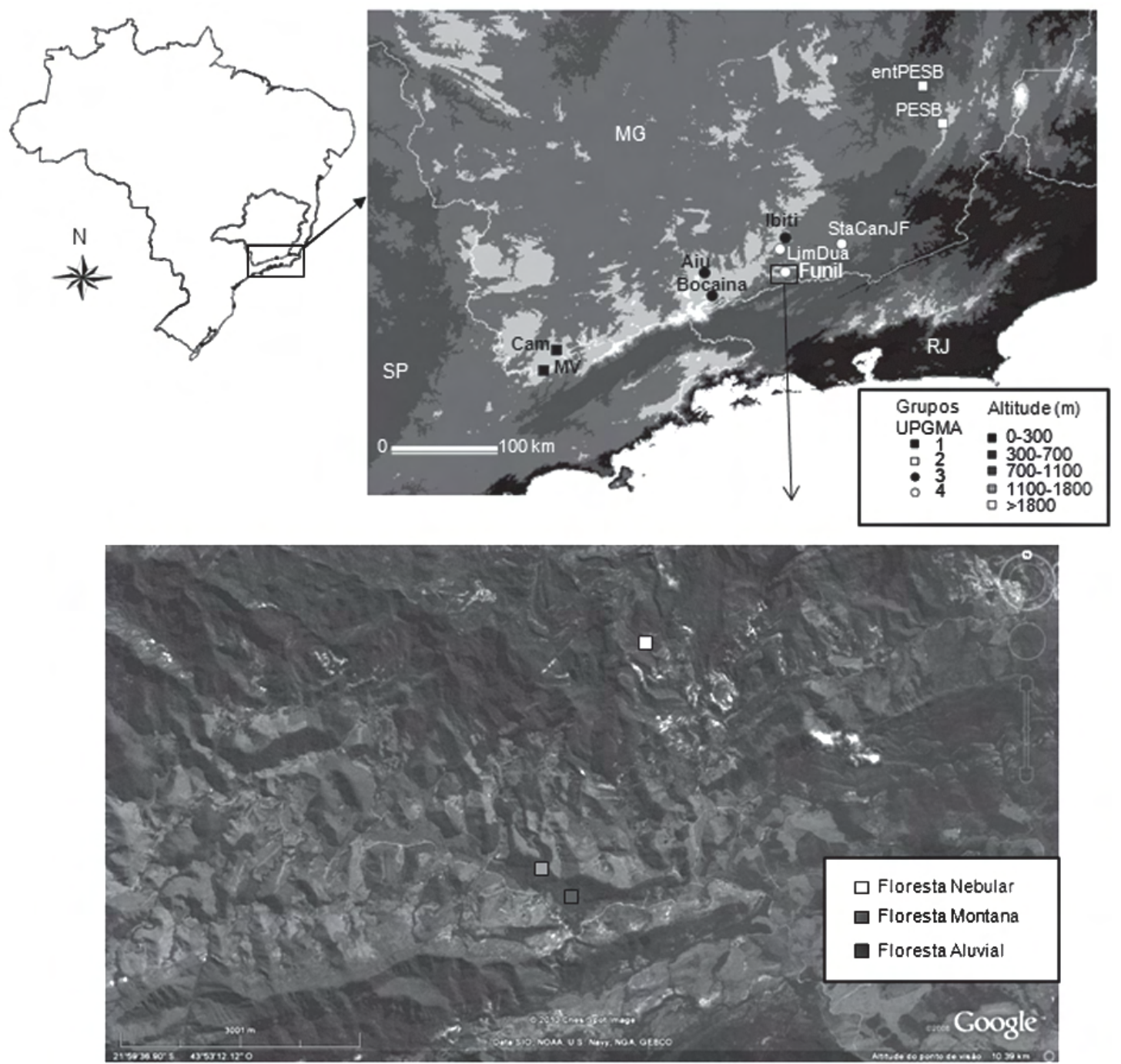

Figura 1 - Mapa com a localização dos três trechos inventariados em um levantamento fitossociológico da comunidade arbórea realizado na Serra Negra, em Rio Preto (MG), e as áreas aplicadas nas análises de similaridade e agrupamento. (imagem Google Earth ${ }^{\mathrm{TM}}$ serviço de mapa)

Figure 1 - Map indicating the location of sampled areas for phytosociology studies in Serra Negra, Rio Preto (MG), and applied areas in the similarity and cluster analysis. (image from Google Earth ${ }^{\mathrm{TM}}$ map service)

Mata montana (21'59'57''S e 4353'27' 'W): trecho interfluvial com 10,7 ha e a 1.000 m de altitude, em relevo ondulado e solo de textura média (Tab. 1). Este fragmento pertenceu à antiga fazenda Funil, limítrofe à mata aluvial. A formação classifica-se como floresta ombrófila densa montana, de acordo com Veloso et al. (1991), e floresta latifoliada pluvial perenifólia tropical inferomontana interfluvial, de acordo com Oliveira-Filho (2009).

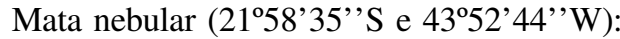
trecho de 4,5 ha situado em faixa altitudinal de 1.300 $\mathrm{m}$, onde predomina o relevo escarpado, de formas abruptas e rochosas. A mata situa-se em fundo de vale, em forma suave côncava ou platô, e o solo é arenoso (Tab. 1). A formação florestal classifica-se como floresta ombrófila densa alto-montana, de acordo com Veloso et al. (1991), e floresta latifoliada nebular perenifólia tropical superomontana interfluvial, de acordo com Oliveira-Filho (2009).

\section{Procedimento de amostragem}

A amostragem fitossociológica ocorreu entre maio de 2005 e dezembro de 2006, pelo método de parcelas (Mueller-Dombois \& Ellemberg 1974). Em 
Tabela 1 - Classe textural e níveis médios dos parâmetros de fertilidade do solo na profundidade de $0-20 \mathrm{~cm}$ nos trechos da mata aluvial, mata montana e mata nebular, Rio Preto, MG. $\mathrm{SB}=$ soma de bases trocáveis $(\mathrm{K}+\mathrm{Ca}+\mathrm{Mg}),(\mathrm{t})=$ Capacidade de Troca Catiônica Efetiva, $(\mathrm{T})=$ Capacidade de Troca Catiônica a ph 7,0, V = Índice de Saturação de Bases, $\mathrm{m}=$ Índice de Saturação de Alumínio, $\mathrm{MO}=$ Matéria orgânica, P-rem = Fósforo remanescente. Análise realizada pelo Departamento de Ciências do Solo, Universidade Federal de Lavras.

Table 1 - Textural class and middle levels of the parameters of soil fertility at a depth of $0-20 \mathrm{~cm}$ in parts of Alluvial Forest, Lower Montane Forest and Cloud Forest, Rio Preto, MG, Brazil. $\mathrm{SB}=$ sum of exchangeable bases $(\mathrm{K}+\mathrm{Ca}+\mathrm{Mg}),(\mathrm{t})=$ Effective Cation Exchange Capacity $(\mathrm{T})=$ Cation Exchange Capacity at $\mathrm{pH} 7.0, \mathrm{~V}=$ Base Saturation Index, $\mathrm{m}=$ Aluminum Saturation Index, OM = Organic Matter, P-rem = Remaining Phosphorus. Analysis by Departamento de Ciências do Solo, Universidade Federal de Lavras.

\begin{tabular}{|c|c|c|c|}
\hline \multirow{3}{*}{$\begin{array}{l}\text { Parâmetros } \\
\text { de fertilidade }\end{array}$} & \multicolumn{3}{|c|}{ Fragmento } \\
\hline & \multicolumn{3}{|c|}{ Classe textural } \\
\hline & Argilosa & Média & Arenosa \\
\hline $\mathrm{pH}\left(\mathrm{H}_{2} \mathrm{O}\right)$ & 3,9 & 4,1 & 3,7 \\
\hline $\mathrm{P} \mathrm{mg} / \mathrm{dm}^{3}$ & 3,1 & 1,4 & 2,8 \\
\hline $\mathrm{K}$ & 47 & 28 & 39 \\
\hline $\mathrm{Ca}^{2+} \mathrm{cmol} / \mathrm{dm}^{3}$ & 0,5 & 0,4 & 0,7 \\
\hline $\mathrm{Mg}^{2+}$ & 0,2 & 0,1 & 0,2 \\
\hline $\mathrm{Al}^{3+}$ & 3,4 & 1,8 & 2,2 \\
\hline $\mathrm{H}+\mathrm{Al}$ & 15,3 & 11 & 11 \\
\hline $\mathrm{SB} \mathrm{cmol}_{\mathrm{c}} / \mathrm{dm}^{3}$ & 0,8 & 0,6 & 1 \\
\hline (t) & 4,2 & 2,4 & 3,2 \\
\hline$(\mathrm{T})$ & 16,1 & 11,6 & 12 \\
\hline $\mathrm{V} \%$ & 5,1 & 4,9 & 8,3 \\
\hline $\mathrm{m}$ & 81 & 76 & 69 \\
\hline MO dag/kg & 5,4 & 3,4 & 3,4 \\
\hline P-rem mg/L & 7,5 & 14,7 & 35,7 \\
\hline
\end{tabular}

cada fragmento foram estabelecidas 25 parcelas contíguas de $10 \times 10 \mathrm{~m}$, totalizando $0,75 \mathrm{ha}$, com os maiores eixos dos blocos de parcelas paralelos às curvas de nível do terreno.

Amostraram-se todos os indivíduos arbóreos ou arborescentes com circunferência a $1,30 \mathrm{~m}$ acima do solo(CAP) maior ou igual a $10 \mathrm{~cm}$, sendo os espécimes perfilhados (múltiplos caules) inventariados quando a circunferênciaquadrática fosseigual ou maior ao critério de inclusão. Os indivíduos receberam plaquetas de alumínio numeradas e tiveram a altura estimada por comparação com vara de alta-poda. As árvores mortas em pé, por dividirem espaço com as demais, foram amostradas e agrupadas na classe "mortas". Os indivíduos não coletados enãoidentificados em campo foram agrupados naclasse "desconhecidas". O material botânico de cada espécie foi coletado, herborizado e, quando fértil, incorporado no acervo do Herbário CESJ da Universidade Federal de Juiz de Fora.

Foram calculados os parâmetros fitossociológicos (Mueller-Dombois \& Ellemberg 1974) para a estrutura horizontal em cada fragmento, processadas pelo software Fitopac 1 (Shepherd 1994), sendo eles: densidade relativa (DR), frequência relativa (FR); dominância relativa (DoR) e valor de importância (VI). Os parâmetros densidade absoluta e área basal computados por parcelas foram comparados através de ANOVAunifatorial associada ao teste de médias de Tukey (Ayres et al. 2007), com a finalidade de diagnosticar diferenças estruturais entre as áreas.

Foram preparados histogramas de frequência da distribuição de indivíduos por classes de diâmetro e altura, que posteriormente foram comparadas pelo teste Qui-Quadrado de partição (Ayres et al.2007) para verificar diferenças entre os fragmentos.

$\mathrm{O}$ índice de diversidade de Shannon, a equabilidade de Pielou e os estimadores de riqueza Jackknife de $1^{\text {a }}$ e $2^{\mathrm{a}}$ ordens foram calculados de acordo com Kent \& Coker (1992). Os índices de diversidade obtidos foram comparados através do procedimento proposto por Hutcheson (Zar 1996).

Os coeficientes de similaridade de Jaccard e Sørensen (Kent \& Coker 1992) foram calculados dentre os três fragmentos estudados e entre a composição florística geral e levantamentos no maciço do Itatiaia, Mantiqueira Sul e Norte e Vale do Paraíba do Sul. As relações florísticas entre a comunidade arbórea da Serra Negra e demais locais foram observadas a partir da construção de um dendrograma com a medida de distância de Sørensen, utilizando o algoritmo UPGMA, através do software PC-Ord 4.0 (McCune \& Mefford 1999).

ComoauxíliodoPC-Ord4.0(McCune \& Mefford 1999), foi efetuada a Análise de Correspondência Destendenciada (DCA) para verificação do gradiente de substituição de espécies arbóreas entre os três fragmentos. A DCA foi efetuada a partir da matriz de abundância das espécies por parcela, eliminando-se aquelas representadas por um único indivíduo.

A identificação das espécies foi feita por meio de comparação com exsicatas depositadas nos herbários CESJ e RB, consulta a especialistas e literatura disponível. A classificação taxonômica foi efetuada segundo o proposto pelo Angiosperm Phylogeny Group (APGII), de acordo com Souza \& 
Lorenzi (2005) para o nível de famílias. As identificações das espécies foram atualizadas seguindo Oliveira-Filho (2006) e Trópicos (2010).

O sistema fitogeográfico adotado na classificação das comunidades inventariadas foi o de Oliveira-Filho \& Fontes (2000), com os domínios e sub-domínios propostos por Oliveira-Filho (2006). Utilizou-se o banco de dados TreeAtlan 1.0 de Oliveira-Filho (2009b) para a descrição da distribuição das espécies pelos tipos florestais.

\section{Resultados}

Para os $7.500 \mathrm{~m}^{2}$ estudados, incluindo as matas aluvial, montana e nebular, foram amostrados 2.572 indivíduos, identificados em 194 espécies, incluídos em 59 famílias e 118 gêneros (Tab. 2). O índice de diversidade de Shannon e a equabilidade de Pielou para o conjunto das três áreas foram, respectivamente, de 4,11 e de 0,76 , sendo que o intervalo estimado para a riqueza específica da comunidade arbórea variou entre 241 e 247 espécies. A riqueza inventariada representou entre 78 e $80 \%$ das espécies esperadas segundo os estimadores Jackknife de $1^{\mathrm{a}}$ e $2^{\mathrm{a}}$ ordens (Tab. 2). Todas as comparações dos índices de Shannon foram significativamente diferentes $(\mathrm{P}<0,001)$ pelo teste de Hutcheson. As famílias com maior riqueza foram Myrtaceae (30 espécies), Lauraceae (20), Melastomataceae (17) e Fabaceae (13). Os gêneros com maior número de espécies foram Ocotea e Miconia (12), Eugenia e Myrcia (8) e Casearia e Solanum (4). As espécies mais abundantes foram Myrciaria tenella (519), Alchornea triplinervia (259), Aparisthmium cordatum (94), Guapira venosa (71), Eugenia widgrenii(63), Psychotria vellosiana (59), Phyllostemonodaphne geminiflora (45), Maytenus salicifolia (40), Myrcia splendens (37), Psychotria stachyoides (34) e Calyptranthes widgreniana (33), correspondendo a $49 \%$ do total.

Analisando-se cada um dos tipos florestais separadamente, verificaram-se níveis inferiores de riqueza e diversidade em relação ao conjunto das áreas, além das diferenças florísticas e estruturais.

Na mata aluvial, foram encontradas 26 espécies (Tab. 3), incluídas em 23 gêneros e 15 famílias, que,

Tabela 2 - Parâmetros de estrutura, abundância, riqueza e diversidade para a sinúsia arbórea nos trechos da mata aluvial, mata montana e mata nebular, Rio Preto, $\mathrm{MG} . \mathrm{DA}=$ densidade de árvores vivas (ind.ha ${ }^{-1}$ ); $\mathrm{AB}=$ área basal dos indivíduos vivos $\left(\mathrm{m}^{2} \mathrm{ha}^{-1}\right) ; \overline{\mathrm{AB}}=$ área basal média dos indivíduos vivos por parcela; $\mathrm{N}=$ número de indivíduos; $\overline{\mathrm{N}}$ = número médio de indivíduos vivos por parcela; $\mathrm{N} . \mathrm{fam}=$ número de famílias; $\mathrm{N} \cdot \mathrm{spp}=$ número de espécies; $\mathrm{H}^{\prime}$ = índice de Shannon; $\mathrm{J}=$ Equabilidade. $\mathrm{S}(\mathrm{jack} 1)$ = estimador de riqueza de espécies de Jackknife de $1^{\mathrm{a}}$ ordem; $\mathrm{S}(\mathrm{jack} 2)=$ estimador de riqueza de espécies de Jackknife de $2^{\mathrm{a}}$ ordem. Diferentes letras evidenciaram diferenças estatísticas significantes ao nível $\alpha=0,05$.

Table 2 - Parameters of abundance, richness and diversity for tree layer of Alluvial Forest, Lower Montane Forest and Cloud Forest, Rio Preto, MG, Brazil.. DA = density of live trees (ind. ha $\left.{ }^{-1}\right) ; \mathrm{AB}=$ basal area of individuals living $\left(\mathrm{m}^{2} \mathrm{ha}^{-1}\right) ; \overline{\mathrm{AB}}=$ average basal area of live individuals per plot; $\mathrm{N}=$ number of individuals; $\overline{\mathrm{N}}=$ average number of individuals alive per plot; $\mathrm{N} . \mathrm{fam}=$ number of families; $\mathrm{N} . s p p=$ number of species, $\mathrm{H}^{\prime}=$ Shannon index, $\mathrm{J}=$ Equability. $\mathrm{S}\left(\right.$ jack1) and $\mathrm{S}\left(\right.$ jack2) $=$ estimator of species richness of the $1^{\text {st }}$ and $2^{\text {nd }}$ order Jackknife, respectively. Distinct letters show significant differences at $\alpha=0.05$.

\begin{tabular}{lcccc}
\hline Área & Aluvial & Montana & Nebular & Conjuntodas áreas \\
\hline $\mathbf{D A}$ & 2.796 & 3.744 & 3.428 & $3.322,66$ \\
$\mathbf{A B}$ & 25,35 & 36,63 & 38,25 & 33,41 \\
$\overline{\mathbf{A B}}$ & $0,253( \pm 0,071)^{\mathrm{a}}$ & $0,366( \pm 0,148)^{\mathrm{b}}$ & $0,382( \pm 0,135)^{\mathrm{b}}$ & $0,334( \pm 0,134)$ \\
$\mathbf{N}$ & 712 & 984 & 876 & 2.572 \\
$\overline{\mathbf{N}}$ & $27,96( \pm 6,87)^{\mathrm{f}}$ & $37,44( \pm 8,7)^{\mathrm{g}}$ & $34,28( \pm 9,23)^{\mathrm{g}}$ & $33,22( \pm 9,12)$ \\
$\mathbf{N . f a m}$ & 15 & 49 & 33 & 59 \\
$\mathbf{N . s p p}$ & 26 & 127 & 84 & 194 \\
$\mathbf{H}$ & $1,3^{\mathrm{I}}$ & $4,19^{\mathrm{J}}$ & $3,42^{\mathrm{K}}$ & 4,11 \\
$\mathbf{J}$ & 0,39 & 0,86 & 0,77 & 0,76 \\
S(jack1) & 35 & 153 & 107 & 241 \\
$\mathbf{S}($ jack2) & 40 & 156 & 115 & 247 \\
\hline
\end{tabular}


somadas às árvores mortas em pé (13 ind.), resultaram em 712 indivíduos. O índice de diversidade de Shannon foi de 1,3 para uma equabilidade de 0,39 (Tab. 2). Dentre as espécies melhor representadas de acordo com o VI destacaram-se Myrciaria tenella, Calyptranthes widgreniana e Alchornea triplinervia que perfizeram $66,4 \%$ do total, sendo que a única que esteve presente em todas as unidades amostrais foi M. tenella (Tab. 3).

$\mathrm{Na}$ mata montana foram encontradas 127 espécies (Tab. 4), incluídas em 92 gêneros e 49 famílias, que, somadas às árvores mortas em pé (48 ind.) e às desconhecidas ( 6 ind.), resultaram em 984 indivíduos. O índice de diversidade de Shannon foi de 4,19 para uma equabilidade de 0,86 (Tab. 2). Myrtaceae (19), Lauraceae (14), Fabaceae (9) e Rubiaceae (7), destacaram-se pela riqueza específica. As 20 espécies de maior VI representaram cerca de $47 \%$ do VI total.

Na mata nebular foram encontradas 84 espécies (Tab. 5), incluídas em 53 gêneros e 33 famílias, que, somadas às árvores mortas em pé (19 ind.) e às desconhecidas (10 ind.), resultaram em 876 indivíduos. O índice de diversidade de Shannon foi de 3,42 para uma equabilidade de 0,86 (Tab. 2). As

Tabela 3 - Parâmetros fitossociológicos das espécies arbóreas amostradas na mata aluvial, na serra Negra, Rio Preto, MG. $\mathrm{N}$ = número de indivíduos; $\mathrm{DR}=$ densidade relativa; $\mathrm{DoR}=$ dominância relativa; $\mathrm{FR}=$ frequência relativa; $\mathrm{VI}=$ valor de importância.

Table 3 - Phytosociological parameters of tree species sampled in Alluvial Forest, Serra Negra, Rio Preto, MG. N = number of individuals; $\mathrm{DR}=$ relative density, $\mathrm{DoR}=$ relative dominance $=\mathrm{FR}=$ relative frequency; $\mathrm{VI}=$ importance value.

\begin{tabular}{lccccc}
\hline Espécies & N & DR & DoR & FR & VI \\
\hline Myrciaria tenella (DC.) O.Berg & 519 & 72,89 & 65,02 & 16,45 & 154,36 \\
Calyptranthes widgreniana O.Berg & 31 & 4,35 & 7,64 & 11,84 & 23,84 \\
Alchornea triplinervia (Spreng.) Müll. Arg. & 38 & 5,34 & 6,58 & 9,21 & 21,13 \\
Mortas & 13 & 1,83 & 5,45 & 7,24 & 14,51 \\
Casearia sylvestris Sw. & 19 & 2,67 & 2,9 & 6,58 & 12,15 \\
Nectandra oppositifolia Nees \& Mart. & 13 & 1,83 & 2,38 & 5,92 & 10,13 \\
Matayba junglandifolia Radlk. & 12 & 1,69 & 1,5 & 6,58 & 9,76 \\
Alchornea sidifolia Müll. Arg. & 10 & 1,4 & 2,88 & 5,26 & 9,55 \\
Sorocea bonplandii (Baill.) W.C.Burger, Lanj. \& Wess.Boer & 8 & 1,12 & 1,3 & 3,95 & 6,37 \\
Vernonanthura divaricata (Spreng.) H.Rob. & 9 & 1,26 & 0,79 & 3,95 & 6 \\
Myrcia guianensis (Aubl.) DC. & 9 & 1,26 & 0,32 & 3,95 & 5,53 \\
Cupania vernalis Cambess. & 5 & 0,7 & 1,22 & 3,29 & 5,21 \\
Peritassa flaviflora A.C.Sm. & 5 & 0,7 & 0,23 & 1,97 & 2,91 \\
Andira fraxinifolia Benth. & 3 & 0,42 & 0,51 & 1,97 & 2,9 \\
Seguieria langsdorfii Moq. & 3 & 0,42 & 0,31 & 1,97 & 2,71 \\
Mimosa bimucronata (DC.) Kuntze & 2 & 0,28 & 0,12 & 1,32 & 1,71 \\
Eugenia cf. melanogyna (D.Legrand) Sobral & 2 & 0,28 & 0,09 & 1,32 & 1,69 \\
Marlierea obscura O.Berg & 2 & 0,28 & 0,08 & 1,32 & 1,67 \\
Casearia lasiophylla Eichler & 1 & 0,14 & 0,2 & 0,66 & 1 \\
Tibouchina estrellensis (Raddi) Cogn. & 1 & 0,14 & 0,11 & 0,66 & 0,91 \\
Ouratea parviflora (DC.) Baill & 1 & 0,14 & 0,1 & 0,66 & 0,89 \\
Zollernia ilicifolia (Brongn.) Vogel & 1 & 0,14 & 0,08 & 0,66 & 0,88 \\
Miconia sp. 2 & 1 & 0,14 & 0,07 & 0,66 & 0,87 \\
Aniba firmula (Nees \& Mart.) Mez & 1 & 0,14 & 0,04 & 0,66 & 0,84 \\
Dictyoloma vandellianum A.Juss. & 1 & 0,14 & 0,04 & 0,66 & 0,84 \\
Miconia stenostachya DC. & 1 & 0,14 & 0,03 & 0,66 & 0,83 \\
Mollinedia schottiana (Spreng.) Perk & 1 & 0,14 & 0,01 & 0,66 & 0,81 \\
\hline & & & & &
\end{tabular}


Tabela 4 - Parâmetros fitossociológicos das espécies arbóreas amostradas na mata montana, na Serra Negra, Rio Preto, $\mathrm{MG}$. $\mathrm{N}$ = número de indivíduos; $\mathrm{DR}=$ densidade relativa; $\mathrm{DoR}=$ dominância relativa; $\mathrm{FR}=$ frequência relativa; $\mathrm{VI}=$ valor de importância.

Table 4 - Phytosociological parameters of tree species sampled in Montane Forest, Serra Negra, Rio Preto, MG. N = number of individuals; $\mathrm{DR}=$ relative density, $\mathrm{DoR}=$ relative dominance $=\mathrm{FR}=$ relative frequency; $\mathrm{VI}=$ importance value.

\begin{tabular}{|c|c|c|c|c|c|}
\hline Espécie & $\mathbf{N}$ & DR & DoR & FR & VI \\
\hline Aparisthmium cordatum (Juss.) Baill. & 94 & 9,55 & 4,58 & 3,35 & 17,48 \\
\hline Mortas & 48 & 4,88 & 5,26 & 3,51 & 13,65 \\
\hline Eugenia widgrenii Sonder ex O.Berg & 63 & 6,40 & 1,66 & 3,19 & 11,26 \\
\hline Xylopia brasiliensis Spreng. & 20 & 2,03 & 6,23 & 2,24 & 10,50 \\
\hline Cryptocarya micrantha Meisn. & 20 & 2,03 & 5,73 & 1,92 & 9,68 \\
\hline Licania kunthiana Hook.f. & 8 & 0,81 & 6,49 & 0,96 & 8,26 \\
\hline Ocotea lancifolia (Schott) Mez & 20 & 2,03 & 4,52 & 1,60 & 8,15 \\
\hline Maytenus salicifolia Reissek & 40 & 4,07 & 1,98 & 2,08 & 8,12 \\
\hline Ocotea odorifera (Vell.) Rohwer & 15 & 1,52 & 3,78 & 1,76 & 7,06 \\
\hline Ocotea aciphylla (Nees) Mez & 12 & 1,22 & 3,98 & 1,44 & 6,64 \\
\hline Abarema langsdorffii (Benth.) Barneby \& J.W.Grimes & 2 & 0,20 & 5,16 & 0,32 & 5,69 \\
\hline Geonoma schottiana Mart. & 27 & 2,74 & 0,28 & 2,56 & 5,58 \\
\hline Virola bicuhyba (Schott) Warb. & 13 & 1,32 & 2,96 & 1,28 & 5,56 \\
\hline Posoqueria latifolia (Rudge) Roem. \& Schult. & 16 & 1,63 & 2,08 & 1,60 & 5,30 \\
\hline Beilschmiedia taubertiana (Schwacke \& Mez) Kosterm. & 20 & 2,03 & 0,95 & 2,24 & 5,22 \\
\hline Lacistema pubescens Mart. & 20 & 2,03 & 0,89 & 2,24 & 5,16 \\
\hline Gymnanthes concolor (Spreng.) Müll.Arg. & 21 & 2,13 & 0,77 & 2,24 & 5,14 \\
\hline Erythroxylum pelleterianum A.St.-Hil. & 21 & 2,13 & 0,50 & 1,92 & 4,55 \\
\hline Miconia cinnamomifolia (DC.) Naudin & 19 & 1,93 & 0,69 & 1,76 & 4,38 \\
\hline Spirotheca rivieri (Decne.) Ulbr. & 17 & 1,73 & 0,54 & 2,08 & 4,34 \\
\hline Copaifera langsdorffii Desf. & 14 & 1,42 & 1,04 & 1,76 & 4,22 \\
\hline Psychotria vellosiana Benth. & 17 & 1,73 & 0,30 & 2,08 & 4,10 \\
\hline Myrcia sp. 3 & 19 & 1,93 & 0,35 & 1,76 & 4,03 \\
\hline Protium heptaphyllum (Aubl.) Marchand & 12 & 1,22 & 1,15 & 1,44 & 3,80 \\
\hline Eugenia acutata Miq. & 13 & 1,32 & 0,51 & 1,92 & 3,75 \\
\hline Eugenia involucrata DC. & 14 & 1,42 & 0,40 & 1,76 & 3,58 \\
\hline Amaioua guianensis Aubl. & 16 & 1,63 & 0,34 & 1,44 & 3,40 \\
\hline Ixora brevifolia Benth. & 9 & 0,91 & 0,93 & 1,44 & 3,28 \\
\hline Tapirira obtusa (Benth.) J.D.Mitch. & 7 & 0,71 & 1,52 & 0,96 & 3,19 \\
\hline Pera glabrata (Schott) Poepp. ex Baill. & 12 & 1,22 & 0,86 & 1,12 & 3,19 \\
\hline Guatteria australis A.St.-Hil. & 9 & 0,91 & 1,05 & 0,96 & 2,92 \\
\hline Coussarea verticillata Müll.Arg. & 13 & 1,32 & 0,62 & 0,96 & 2,90 \\
\hline Ocotea aff. lobbii (Meisn.) Rohwer & 7 & 0,71 & 1,18 & 0,96 & 2,85 \\
\hline Guapira graciliflora (Schmidt) Lundell & 8 & 0,81 & 0,77 & 1,12 & 2,70 \\
\hline Byrsonima myricifolia Griseb. & 5 & 0,51 & 1,32 & 0,80 & 2,63 \\
\hline Sloanea stipitata Spruce ex Benth. & 7 & 0,71 & 1,19 & 0,64 & 2,54 \\
\hline Protium spruceanum (Benth.) Engl. & 8 & 0,81 & 0,56 & 1,12 & 2,50 \\
\hline Prunus myrtifolia (L.) Urb. & 9 & 0,91 & 0,38 & 1,12 & 2,42 \\
\hline Copaifera trapezifolia Hayne & 10 & 1,02 & 0,42 & 0,96 & 2,40 \\
\hline Myrcia splendens (Sw.) DC. & 7 & 0,71 & 0,69 & 0,96 & 2,36 \\
\hline
\end{tabular}




\begin{tabular}{|c|c|c|c|c|c|}
\hline Espécie & $\mathbf{N}$ & DR & DoR & FR & VI \\
\hline Byrsonima laxiflora Griseb. & 5 & 0,51 & 1,18 & 0,64 & 2,33 \\
\hline Desconhecida & 6 & 0,61 & 0,75 & 0,96 & 2,32 \\
\hline Matayba juglandifolia Radlk. & 7 & 0,71 & 0,48 & 1,12 & 2,31 \\
\hline Mollinedia widgrenii A.DC. & 8 & 0,81 & 0,32 & 1,12 & 2,25 \\
\hline Neomitranthes sp. 1 & 10 & 1,02 & 0,21 & 0,96 & 2,19 \\
\hline Alchornea triplinervia(Spreng.) Müll.Arg. & 3 & 0,30 & 1,32 & 0,48 & 2,10 \\
\hline Laplacea fruticosa (Schrad.) Kobuski & 3 & 0,30 & 1,30 & 0,48 & 2,08 \\
\hline Duguetia lanceolata A.S t.-Hil. & 7 & 0,71 & 0,85 & 0,32 & 1,88 \\
\hline Pouteria gardneriana (A.DC.) Radlk. & 2 & 0,20 & 1,34 & 0,32 & 1,86 \\
\hline Casearia arborea (Rich.) Urb. & 3 & 0,30 & 1,20 & 0,32 & 1,83 \\
\hline Tabernaemontana laeta Mart. & 8 & 0,81 & 0,19 & 0,80 & 1,80 \\
\hline Guapira opposita (Vell.) Reitz & 6 & 0,61 & 0,20 & 0,96 & 1,77 \\
\hline Sloanea guianensis (Aubl.) Benth. & 3 & 0,30 & 0,94 & 0,48 & 1,72 \\
\hline Campomanesia cf. lundiana (O.Berg) Kiaersk. & 4 & 0,41 & 0,61 & 0,64 & 1,66 \\
\hline Miconia urophylla DC. & 7 & 0,71 & 0,13 & 0,80 & 1,64 \\
\hline Myrsine umbellata Mart. & 7 & 0,71 & 0,22 & 0,64 & 1,57 \\
\hline Garcinia brasiliensis Mart. & 5 & 0,51 & 0,26 & 0,80 & 1,57 \\
\hline Cybianthus peruvianus (A.DC.) Miq. & 6 & 0,61 & 0,16 & 0,80 & 1,57 \\
\hline Guapira venosa (Choisy) Lundell & 5 & 0,51 & 0,17 & 0,80 & 1,48 \\
\hline Dalbergia nigra (Vell.) Allemão ex Benth. & 2 & 0,20 & 0,95 & 0,32 & 1,48 \\
\hline Hirtella glandulosa Spreng. & 3 & 0,30 & 0,68 & 0,48 & 1,47 \\
\hline Jacaranda puberula Cham. & 4 & 0,41 & 0,35 & 0,64 & 1,39 \\
\hline Vochysia schwackeana Warm. & 5 & 0,51 & 0,18 & 0,64 & 1,33 \\
\hline Quiina glaziovii Engl. & 2 & 0,20 & 0,92 & 0,16 & 1,28 \\
\hline Vernonanthura divaricata (Spreng.) H.Rob. & 3 & 0,30 & 0,43 & 0,48 & 1,22 \\
\hline Maytenus glazioviana Loes. & 2 & 0,20 & 0,68 & 0,32 & 1,21 \\
\hline Qualea gestasiana A.St.-Hil. & 2 & 0,20 & 0,68 & 0,32 & 1,21 \\
\hline Chrysochlamys saldanhae (Engl.) Oliveira-Filho & 6 & 0,61 & 0,10 & 0,48 & 1,19 \\
\hline Cheiloclinium cognatum (Miers.) A.C.Sm. & 2 & 0,20 & 0,65 & 0,32 & 1,18 \\
\hline Miconia tristis Spring & 4 & 0,41 & 0,13 & 0,64 & 1,18 \\
\hline Miconia sp.4 & 4 & 0,41 & 0,44 & 0,32 & 1,17 \\
\hline Ocotea corymbosa (Meisn.) Mez & 4 & 0,41 & 0,12 & 0,64 & 1,16 \\
\hline Leucochloron incuriale (Vell.) Barneby \& J.W.Grimes & 4 & 0,41 & 0,09 & 0,64 & 1,14 \\
\hline Myrcia cf. palustris DC. & 4 & 0,41 & 0,07 & 0,64 & 1,11 \\
\hline Ouratea parviflora (DC.) Baill. & 4 & 0,41 & 0,05 & 0,64 & 1,10 \\
\hline Calyptranthes widgreniana O.Berg & 2 & 0,20 & 0,52 & 0,32 & 1,04 \\
\hline Lamanonia ternata Vell. & 1 & 0,10 & 0,76 & 0,16 & 1,02 \\
\hline Allophylus edulis (A.St.-Hil., Cambess. \& A.Juss.) Radlk. & 3 & 0,30 & 0,32 & 0,32 & 0,94 \\
\hline Vismia magnoliifolia Schltdl. \& Cham. & 3 & 0,30 & 0,31 & 0,32 & 0,93 \\
\hline Micropholis gardneriana (A.DC.) Pierre & 3 & 0,30 & 0,10 & 0,48 & 0,88 \\
\hline Cupania ludowigii Somner \& Ferruci & 3 & 0,30 & 0,24 & 0,32 & 0,87 \\
\hline Daphnopsis coriacea Taub. & 3 & 0,30 & 0,05 & 0,48 & 0,84 \\
\hline Chomelia sericea Müll.Arg. & 3 & 0,30 & 0,05 & 0,48 & 0,83 \\
\hline Maprounea guianensis Aubl. & 2 & 0,20 & 0,31 & 0,32 & 0,83 \\
\hline Picramnia glazioviana Engl. & 3 & 0,30 & 0,05 & 0,48 & 0,83 \\
\hline
\end{tabular}




\begin{tabular}{|c|c|c|c|c|c|}
\hline Espécie & $\mathbf{N}$ & DR & DoR & FR & VI \\
\hline Myrcia guianensis (Aubl.) DC. & 3 & 0,30 & 0,04 & 0,48 & 0,82 \\
\hline Guarea macrophylla Vahl & 3 & 0,30 & 0,03 & 0,48 & 0,82 \\
\hline Platypodium elegans Vogel & 1 & 0,10 & 0,55 & 0,16 & 0,81 \\
\hline Heisteria silvianii Schwacke & 2 & 0,20 & 0,28 & 0,32 & 0,80 \\
\hline Ocotea bicolor Vattimo-Gil & 2 & 0,20 & 0,42 & 0,16 & 0,78 \\
\hline Ocotea minarum (Nees) Mez & 2 & 0,20 & 0,12 & 0,32 & 0,64 \\
\hline Terminalia cf. triflora (Griseb.) Lillo & 2 & 0,20 & 0,12 & 0,32 & 0,64 \\
\hline Sacoglottis mattogrossensis Malme & 2 & 0,20 & 0,11 & 0,32 & 0,63 \\
\hline Styrax pohlii A.DC. & 2 & 0,20 & 0,10 & 0,32 & 0,63 \\
\hline Cabralea canjerana (Vell.) Mart. & 3 & 0,30 & 0,15 & 0,16 & 0,61 \\
\hline Sloanea monosperma Vell. & 2 & 0,20 & 0,07 & 0,32 & 0,59 \\
\hline Aniba firmula (Nees \& Mart.) Mez & 2 & 0,20 & 0,07 & 0,32 & 0,59 \\
\hline Tapirira guianensis Aubl. & 2 & 0,20 & 0,06 & 0,32 & 0,58 \\
\hline Ilex theezans Mart. ex Reissek & 2 & 0,20 & 0,05 & 0,32 & 0,58 \\
\hline Cordia trichotoma (Vell.) Arrab. ex Steud. & 2 & 0,20 & 0,05 & 0,32 & 0,58 \\
\hline Eugenia cerasiflora Miq. & 2 & 0,20 & 0,04 & 0,32 & 0,56 \\
\hline Capsicodendron dinisii (Schwacke) Occhioni & 1 & 0,10 & 0,30 & 0,16 & 0,56 \\
\hline Solanum pseudoquina A.St.-Hil. & 2 & 0,20 & 0,03 & 0,32 & 0,56 \\
\hline Schefflera morototoni (Aubl.) Maguire et al. & 2 & 0,20 & 0,02 & 0,32 & 0,55 \\
\hline Persea sp. & 1 & 0,10 & 0,24 & 0,16 & 0,50 \\
\hline Trichilia emarginata (Turcz.) C.DC. & 1 & 0,10 & 0,22 & 0,16 & 0,48 \\
\hline Kielmeyera coriacea Mart. \& Zucc. & 1 & 0,10 & 0,21 & 0,16 & 0,47 \\
\hline Eugenia brasiliensis Lam. & 2 & 0,20 & 0,09 & 0,16 & 0,45 \\
\hline Neomitranthes sp. 2 & 2 & 0,20 & 0,07 & 0,16 & 0,44 \\
\hline Lithraea molleoides (Vell.) Engl. & 1 & 0,10 & 0,16 & 0,16 & 0,42 \\
\hline Siphoneugena densiflora O.Berg & 1 & 0,10 & 0,14 & 0,16 & 0,40 \\
\hline Dictyoloma vandellianum A.Juss. & 1 & 0,10 & 0,12 & 0,16 & 0,38 \\
\hline Eugenia sp. 2 & 1 & 0,10 & 0,10 & 0,16 & 0,36 \\
\hline Inga tenuis (Vell.) Mart. & 1 & 0,10 & 0,09 & 0,16 & 0,35 \\
\hline Persea sp. 2 & 1 & 0,10 & 0,05 & 0,16 & 0,31 \\
\hline Xylosma prockia (Turcz.) Turcz. & 1 & 0,10 & 0,03 & 0,16 & 0,29 \\
\hline Marlierea laevigata (DC.) Kiaersk. & 1 & 0,10 & 0,03 & 0,16 & 0,29 \\
\hline Psidium myrtoides O.Berg & 1 & 0,10 & 0,02 & 0,16 & 0,29 \\
\hline $\begin{array}{l}\text { Pseudopiptadenia warmingii (Benth.) } \\
\text { G.P.Lewis \& M.P.Lima }\end{array}$ & 1 & 0,10 & 0,02 & 0,16 & 0,28 \\
\hline Agonandra excelsa Griseb. & 1 & 0,10 & 0,02 & 0,16 & 0,28 \\
\hline Siphoneugena widgreniana O.Berg & 1 & 0,10 & 0,01 & 0,16 & 0,27 \\
\hline Ocotea glaziovii Mez & 1 & 0,10 & 0,01 & 0,16 & 0,27 \\
\hline Psychotria suterella Müll.Arg. & 1 & 0,10 & 0,01 & 0,16 & 0,27 \\
\hline Myrsine coriacea (Sw.) Roem. \& Schult. & 1 & 0,10 & 0,01 & 0,16 & 0,27 \\
\hline Miconia sp. 1 & 1 & 0,10 & 0,01 & 0,16 & 0,27 \\
\hline Chrysophyllum gonocarpum (Mart. \& Eichler) Engl. & 1 & 0,10 & 0,01 & 0,16 & 0,27 \\
\hline Ormosia arborea (Vell.) Harms & 1 & 0,10 & 0,01 & 0,16 & 0,27 \\
\hline Eugenia sp. 1 & 1 & 0,10 & 0,01 & 0,16 & 0,27 \\
\hline Ocotea diospyrifolia (Meisn.) Mez & 1 & 0,10 & 0,01 & 0,16 & 0,27 \\
\hline
\end{tabular}


Tabela 5 - Parâmetros fitossociológicos das espécies arbóreas amostradas na mata nebular, na Serra Negra, Rio Preto, $\mathrm{MG} . . \mathrm{N}$ = número de indivíduos; $\mathrm{DR}=$ densidade relativa; $\mathrm{DoR}=$ dominância relativa; $\mathrm{FR}=$ frequência relativa; A.Med. = altura média; VI = valor de importância.

Table 5 - Phytosociological parameters of tree species sampled in Cloud Forest, Serra Negra, Rio Preto, MG. N = number of individuals; $\mathrm{DR}=$ relative density, $\mathrm{DoR}=$ relative dominance $=\mathrm{FR}=$ relative frequency; $\mathrm{VI}=$ importance value.

\begin{tabular}{|c|c|c|c|c|c|}
\hline Espécies & $\mathbf{N}$ & DR & DoR & FR & VI \\
\hline Alchornea triplinervia (Spreng.) Müll. Arg. & 218 & 24,89 & 41,96 & 5,85 & 72,70 \\
\hline Solanum cinnamomeum Sendtn. & 18 & 2,05 & 11,00 & 3,28 & 16,34 \\
\hline Guapira venosa (Choisy) Lundell & 64 & 7,31 & 3,88 & 4,92 & 16,11 \\
\hline Phyllostemonodaphne geminiflora (Mez) Kosterm. & 45 & 5,14 & 1,54 & 3,98 & 10,66 \\
\hline Psychotria velloziana Benth. & 41 & 4,68 & 1,57 & 3,28 & 9,53 \\
\hline Solanum leucodendron Sendtn. & 20 & 2,28 & 3,58 & 3,51 & 9,37 \\
\hline Myrcia splendens (Sw.) DC. & 30 & 3,42 & 1,55 & 3,28 & 8,26 \\
\hline Morto & 19 & 2,17 & 2,45 & 2,81 & 7,43 \\
\hline Psychotria stachyoides Benth. & 34 & 3,88 & 0,71 & 2,58 & 7,17 \\
\hline Cordia trichoclada DC. & 7 & 0,80 & 4,68 & 1,17 & 6,65 \\
\hline Myrcia fenzliana O.Berg & 14 & 1,60 & 2,41 & 2,58 & 6,58 \\
\hline Annona cacans Warm. & 20 & 2,28 & 1,42 & 2,81 & 6,52 \\
\hline Prunus myrtifolia (L.) Urb. & 10 & 1,14 & 3,03 & 2,11 & 6,27 \\
\hline Miconia urophylla DC. & 16 & 1,83 & 0,36 & 3,28 & 5,47 \\
\hline Tibouchina granulosa (Desr.) Cogn. & 9 & 1,03 & 2,67 & 1,41 & 5,11 \\
\hline Guatteria australis A.St-Hil. & 17 & 1,94 & 0,46 & 2,11 & 4,51 \\
\hline Ilex paraguariensis A.St.-Hil. & 13 & 1,48 & 0,54 & 2,34 & 4,36 \\
\hline Drymis brasiliensis Miers & 12 & 1,37 & 0,36 & 2,34 & 4,08 \\
\hline Tibouchina sp 3 & 9 & 1,03 & 1,45 & 1,41 & 3,88 \\
\hline Desconhecida & 10 & 1,14 & 0,59 & 2,11 & 3,84 \\
\hline Miconia buddlejoides Triana & 13 & 1,48 & 0,20 & 2,11 & 3,79 \\
\hline Cecropia hololeuca Miq. & 4 & 0,46 & 2,35 & 0,94 & 3,74 \\
\hline Inga sessilis (Vell.) Mart. & 10 & 1,14 & 0,61 & 1,87 & 3,62 \\
\hline Myrcia sp1 & 13 & 1,48 & 0,23 & 1,64 & 3,35 \\
\hline Myrcia sp2 & 14 & 1,60 & 0,36 & 1,17 & 3,13 \\
\hline Cyathea delgadii Sternb. & 7 & 0,80 & 0,69 & 1,64 & 3,13 \\
\hline Aegiphila sellowiana Cham. & 10 & 1,14 & 0,78 & 1,17 & 3,09 \\
\hline Geonoma schottiana Mart. & 9 & 1,03 & 0,13 & 1,87 & 3,03 \\
\hline Posoqueira latifolia (Rudge) Roem. \& Schult. & 9 & 1,03 & 0,31 & 1,64 & 2,98 \\
\hline Cabralea canjerana (Vell.) Mart. & 10 & 1,14 & 0,32 & 1,41 & 2,86 \\
\hline Myrcia guianensis (Aubl.) DC. & 10 & 1,14 & 0,13 & 1,41 & 2,68 \\
\hline Chomelia sericea Müll.Arg. & 7 & 0,80 & 0,34 & 1,41 & 2,54 \\
\hline Mollinedia triflora (Spreng.) Tul. & 10 & 1,14 & 0,30 & 0,94 & 2,38 \\
\hline Euterpe edulis Mart. & 6 & 0,68 & 0,20 & 1,41 & 2,29 \\
\hline Miconia cinnamomifolia (DC.) Naudin & 6 & 0,68 & 0,29 & 1,17 & 2,15 \\
\hline Cupania vernalis Cambess. & 6 & 0,68 & 0,29 & 1,17 & 2,15 \\
\hline Eugenia widgrenii Sonder ex O.Berg & 7 & 0,80 & 0,12 & 1,17 & 2,09 \\
\hline Coussarea verticillata Müll.Arg. & 8 & 0,91 & 0,17 & 0,94 & 2,02 \\
\hline Miconia tentaculifera Naudin & 6 & 0,68 & 0,18 & 0,94 & 1,80 \\
\hline Meriania claussenii Triana & 1 & 0,11 & 1,43 & 0,23 & 1,77 \\
\hline Cordia silvestris Fresen. & 6 & 0,68 & 0,36 & 0,70 & 1,74 \\
\hline
\end{tabular}




\begin{tabular}{|c|c|c|c|c|c|}
\hline Espécies & $\mathbf{N}$ & DR & DoR & FR & VI \\
\hline Citronella paniculata (Mart.) R.A.Howard & 4 & 0,46 & 0,20 & 0,94 & 1,60 \\
\hline Guapira opposita (Vell.) Reitz & 4 & 0,46 & 0,14 & 0,70 & 1,30 \\
\hline Vernonanthura divaricata (Spreng.) H.Rob. & 2 & 0,23 & 0,60 & 0,47 & 1,30 \\
\hline Ocotea dispersa (Nees) Mez & 4 & 0,46 & 0,12 & 0,70 & 1,28 \\
\hline Piptocarpha macropoda Baker & 3 & 0,34 & 0,35 & 0,47 & 1,16 \\
\hline Seguieria langsdorfii Moq. & 4 & 0,46 & 0,21 & 0,47 & 1,14 \\
\hline Ocotea corymbosa (Meisn.) Mez & 2 & 0,23 & 0,35 & 0,47 & 1,05 \\
\hline Miconia doriana Cogn. & 4 & 0,46 & 0,06 & 0,47 & 0,98 \\
\hline Cryptocarya micrantha Meisn. & 3 & 0,34 & 0,06 & 0,47 & 0,87 \\
\hline Tibouchina mutabilis Cogn. & 2 & 0,23 & 0,17 & 0,47 & 0,86 \\
\hline Sloanea guianensis (Aubl.) Benth. & 2 & 0,23 & 0,14 & 0,47 & 0,83 \\
\hline Aspidosperma olivaceum Müll.Arg. & 2 & 0,23 & 0,12 & 0,47 & 0,82 \\
\hline Ocotea catharinensis $\mathrm{Mez}$ & 2 & 0,23 & 0,10 & 0,47 & 0,80 \\
\hline Myrceugenia sp. & 2 & 0,23 & 0,08 & 0,47 & 0,77 \\
\hline Macropeplus dentatus (Perkins) I.Santos \& Peixoto & 2 & 0,23 & 0,04 & 0,47 & 0,74 \\
\hline Ocotea laxa (Nees) Mez & 2 & 0,23 & 0,04 & 0,47 & 0,74 \\
\hline Byrsonima lancifolia A.Juss. & 2 & 0,23 & 0,04 & 0,47 & 0,74 \\
\hline Clethra scabra Pers. & 2 & 0,23 & 0,04 & 0,47 & 0,74 \\
\hline Pimenta pseudocaryophyllus (Gomes) Landrum & 2 & 0,23 & 0,03 & 0,47 & 0,73 \\
\hline Aspidosperma australe Müll.Arg. & 1 & 0,11 & 0,23 & 0,23 & 0,58 \\
\hline Ocotea glaziovii Mez & 2 & 0,23 & 0,05 & 0,23 & 0,52 \\
\hline Ocotea $\mathrm{sp} 1$ & 1 & 0,11 & 0,17 & 0,23 & 0,51 \\
\hline Miconia cinerascens Miq. & 2 & 0,23 & 0,04 & 0,23 & 0,50 \\
\hline Casearia sylvestris $\mathrm{Sw}$ & 1 & 0,11 & 0,10 & 0,23 & 0,45 \\
\hline Hirtella hebeclada Moric. ex DC. & 1 & 0,11 & 0,07 & 0,23 & 0,41 \\
\hline Pouteria gardneriana (A.DC.) Radlk. & 1 & 0,11 & 0,05 & 0,23 & 0,40 \\
\hline Casearia decandra Jacq. & 1 & 0,11 & 0,04 & 0,23 & 0,39 \\
\hline Ocotea minarum (Nees) $\mathrm{Mez}$ & 1 & 0,11 & 0,04 & 0,23 & 0,39 \\
\hline Rudgea jasminoides (Cham.) Müll.Arg. & 1 & 0,11 & 0,04 & 0,23 & 0,39 \\
\hline Myrsine coriacea (Sw.) Roem. \& Schult. & 1 & 0,11 & 0,03 & 0,23 & 0,38 \\
\hline Eugenia sp1 & 1 & 0,11 & 0,03 & 0,23 & 0,37 \\
\hline Quiina margallano-gomesii Schwacke & 1 & 0,11 & 0,03 & 0,23 & 0,37 \\
\hline Marlierea laevigata (DC.) Kiaersk. & 1 & 0,11 & 0,02 & 0,23 & 0,37 \\
\hline Amaioua guianensis Aubl. & 1 & 0,11 & 0,02 & 0,23 & 0,37 \\
\hline Miconia mellina DC. & 1 & 0,11 & 0,02 & 0,23 & 0,37 \\
\hline Sparattosperma leucanthum (Vell.) K.Schum. & 1 & 0,11 & 0,02 & 0,23 & 0,37 \\
\hline Persea willdenowii Kosterm. & 1 & 0,11 & 0,02 & 0,23 & 0,36 \\
\hline Solanum bullatum Vell. & 1 & 0,11 & 0,02 & 0,23 & 0,36 \\
\hline Miconia sp. 3 & 1 & 0,11 & 0,01 & 0,23 & 0,36 \\
\hline Guapira graciliflora (Schmidt) Lundell & 1 & 0,11 & 0,01 & 0,23 & 0,36 \\
\hline Myrcia hebepetala DC. & 1 & 0,11 & 0,01 & 0,23 & 0,36 \\
\hline Ocotea diospyrifolia (Meisn.) Mez & 1 & 0,11 & 0,01 & 0,23 & 0,36 \\
\hline Myrceugenia myrcioides (Cambess.) O.Berg & 1 & 0,11 & 0,01 & 0,23 & 0,36 \\
\hline Calyptranthes grandifolia O.Berg & 1 & 0,11 & 0,01 & 0,23 & 0,36 \\
\hline Matayba guianensis Aubl. & 1 & 0,11 & 0,01 & 0,23 & 0,36 \\
\hline
\end{tabular}


famílias com maior riqueza específica foram Myrtaceae, com 13 espécies, Melastomataceae (11), Lauraceae (11) e Rubiaceae (6). As espécies que perfizeram $49 \%$ do VI corresponderam às 10 espécies de maior valor de importância no trecho nebular.

\section{Estrutura vertical}

A distribuição dos indivíduos em classes de altura revelou, para a mata aluvial, que $83,5 \%$ destes apresentaram altura entre 4-8 m, enquanto este valor correspondeu a $54,5 \%$ e $48,7 \%$ na mata montana e nebular, respectivamente (Fig. 4). Na mata aluvial não foram verificados espécimes com altura superior a $16 \mathrm{~m}$ (Fig. 4) e apenas na mata montana foram amostradas árvores com altura superior a $20 \mathrm{~m}$. A distribuição de frequência dos indivíduos por classes de altura entre os trechos evidenciou diferenças significativas $\left(\chi_{0,05 ; 20}^{2}=331,4\right.$; $\mathrm{p}<0,0001$ ), proporcionadas principalmente pelas maiores abundâncias observadas de plantas com altura entre 4-6 m, na mata aluvial e com altura entre $12-18 \mathrm{~m}$, na mata nebular. Também foram verificadas abundâncias inferiores à esperada de árvores na primeira classe de alturae de indivíduos com altura superior a $8 \mathrm{~m}$, na mata aluvial.

$\mathrm{Na}$ mata aluvial verificou-se um dossel fisionomicamente mais homogêneo quando comparado às demais áreas, resultante da representatividade de Myrciaria tenella neste trecho, que apresentou altura média de 5,58 m ( \pm $1,00)$. Outras espécies destacaram-se devido à altura, como emergentes, incluindo: Calyptranthes widgreniana, Alchornea triplinervia, Casearia sylvestris, Nectandra oppositifolia, Matayba juglandifolia e A. sidifolia.

Na mata montana, o subosque foi representado principalmente por Geonoma schottiana e Myrcia cf. palustris, seguidas de Picramnia glazioviana e Guarea macrophylla. Os indivíduos com altura igual ou superior a $20 \mathrm{~m}$ na mata montana corresponderam às espécies Abarema langsdorffii, Cryptocarya micrantha, Lamanonia ternata, Laplacea fruticosa, Licania kunthiana, Ocotea aciphylla, O. odorifera, Platypodium elegans, Pouteria gardneriana, Tapirira obtusa e Xylopia brasiliensis.

Na mata nebular, destacou-se no subosque Psychotria stachyoides, espécie de menor porte e abundante neste trecho (Tab. 5). As espécies com maior altura na mata nebular $(18 \mathrm{~m}<\mathrm{h} \leq 20 \mathrm{~m})$ foram Alchornea triplinervia, Cecropia hololeuca, Cordia trichoclada, Myrcia fenzliana,
Myrcia splendens, Prunus myrtifolia, Solanum cinnamomeum, Tibouchina granulosa e Vernonanthura divaricata.

\section{Estrutura horizontal}

A densidade estimada por área variou entre 2.796 indivíduos vivos por hectare na mata aluvial à 3.744 indivíduos na mata montana, com diferenças significativas entre as áreas $\left(\mathrm{F}_{0,05(1), 2,72}=8,39 ; \mathrm{p}=\right.$ 0,0008 ) (Tab. 2). A mata aluvial apresentou menor densidade média quando comparada à mata montana $(\mathrm{q}=5,69 ; \mathrm{p}<0,01)$ e matamebular $(\mathrm{q}=3,79 ; \mathrm{p}<0,05)$, sendo que as últimas não diferiram entre $\operatorname{si}(\mathrm{q}=1,89$; $\mathrm{p}>0,05$ ) (Tab. 2). Resultado semelhante foi observado para área basal, havendo diferenças significativas entre as áreas $\left(\mathrm{F}_{0.05(1), 72}=8,14 ; \mathrm{p}=\right.$ $0,001)$. A mata aluvial apresentou a menor área basal média (Tab. 2) quando comparada àquelas obtidas para mata montana $(\mathrm{q}=4,57 ; \mathrm{p}<0,01)$ e mata nebular $(q=5,23 ; p<0,01)$. Não houve diferença significativa entre as áreas basais médias registradas para mata montana e mata nebular $(q=0,65 ; \mathrm{p}>0,05)$. Ao reunir as três áreas em um único conjunto, a densidade absoluta de indivíduos vivos foi de 3.322,66 ind./ha e a área basal equivaleu a $33,41 \mathrm{~m}^{2} / \mathrm{ha}$ (Tab. 2).

$\mathrm{Na}$ mata aluvial, dos 712 indivíduos amostrados (incluindo a categoria "mortas"), 62,2\% (443) apresentaram perfilhamento (Pti) e, das 26 espécies, $57 \%$ continham ao menos um indivíduo perfilhado (Ps) (Fig. 2).

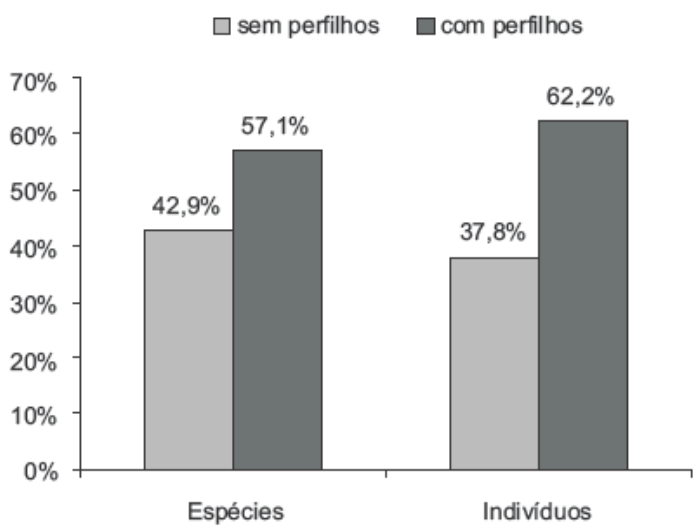

Figura 2 - Relações entre espécies e indivíduos arbóreos perfilhados e não perfilhados em um levantamento fitossociológico no trecho de mata aluvial, em Rio Preto, MG.

Figure 2-Branching relations among species and individuals sampled in the alluvial forest, Rio Preto, MG. 
Houve diferença significativa na distribuição de indivíduos por classe de diâmetro entre os trechos $\left(\chi_{0,05 ; 8}^{2}=123,8 ; \mathrm{p}<0,0001\right)$, havendo na mata aluvial menor densidade de indivíduos no intervalo de diâmetro entre $3,3-4,8 \mathrm{~cm}$, quando comparado ao esperado (Fig. 3). Na mata montana, quando comparado ao esperado, ocorreu maior abundância de indivíduos com diâmetro até $4,8 \mathrm{~cm}$, porém, houve ainda uma carência de árvores com diâmetroentre 9,8-39,2 cm, enquanto na mata nebular verificou-se menor abundância de indivíduos com diâmetro entre 9,8-19,6 cm e um aumento de espécimes com diâmetro entre 19,6-39,2 cm.

Ressalta-se que, na mata aluvial, a dominância relativa de Myrciaria tenella explicou 65\% da área basal na comunidade, valor este muito superior ao de Calyptranthes widgreniana (7,64\%), na segunda posição. Os maiores valores de dominância relativa foram diretamente relacionados com a posição hierárquica dos valores de importância.

A correspondência entre dominância relativa e valor de importância não ocorreu para a mata montana. Entre as dez espécies de maior valor de importância, a maior dominância foi observada em Licania kunthiana, na quinta posição em VI. Em contraposição, a espécie de maior importância, Aparisthmium cordatum, obteve a quinta maior dominância. Essa espécie se destacou em função dos valores mais altos de densidade e frequência (Tab. 4). Situação similar foi verificada para Eugenia widgrenii, na segunda posição de VI, mesmo com a menor dominância entre as dez principais espécies. Na mata montana, Xylopia brasiliensisfoi inventariada com indivíduos de grande porte e regularmente distribuídos pelas unidades amostrais, o que conferiu elevados parâmetros de dominânciae frequência, com consequente destaque fitossociológico. Ocotea lancifolia, Ocotea odoriferae Abarema langsdorfii, apresentaram altos valores de dominância, o que repercutiu nos valores de importância.

Na mata nebular, com $41,96 \%$ de dominância, Alchornea triplinervia foi a espécie com maior VI, seguida por Solanum cinnamomeum (11\%). Guapira venosa, Phyllostemonodaphne geminiflora, Psychotria stachyoides e Psychotria vellosiana compuseram o subosque e apresentaram valores elevados de densidade e frequência e menores dominâncias.

Houve baixa similaridade entre as três áreas (Tab. 6), sendo as maiores semelhanças observadas entre as matas montana e nebular, enquanto as menores ocorreramentre as matas montana e aluvial. No diagrama de Venn (Fig. 5) observou-se que apenas

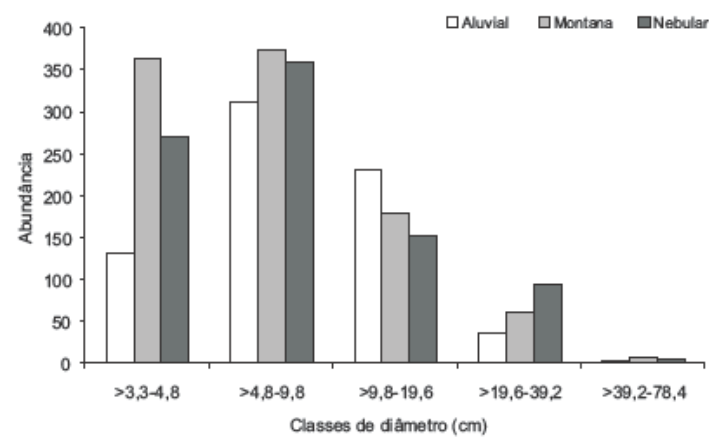

Figura 3 - Distribuição de frequência em classes de diâmetro dos indivíduos arbóreos amostrados em três trechos florestais, na Serra Negra, Rio Preto, MG.

Figure 3 - Frequency distribution in diameter classes of individuals sampled in three forest types, Rio Preto, MG.

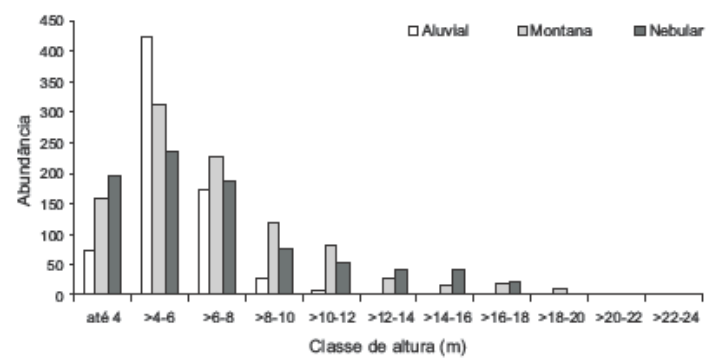

Figura 4 - Distribuição de frequência em classes de altura dos indivíduos arbóreos amostrados em três trechos florestais, na Serra Negra, Rio Preto, MG.

Figure 4 -Frequency distribution in height classes of individuals sampled in three forest types, Rio Preto, MG.

três espécies foram comuns às três áreas, sendo elas Alchornea triplinervia, Myrcia guianensis e Vernonanthura divaricata. Embora a similaridade tenha sido menor entre a mata aluvial e montana, entre elas houve duas espécies a mais e em comum, do que entre as matas aluvial e nebular. Ainda, estas áreas apresentaram diferenças significativas entre os índices de diversidade de Shannon (Tab. 2), com destaque para a elevada diversidade da mata montana.

A análise de correspondência destendenciada (DCA) (Fig. 6) produziu autovalores elevados para o eixo $1(0,908)$ e baixos para o eixo $2(0,226)$, evidenciando o gradiente de substituição de espécies (ter Braak 1995). O eixo 1 apresentou coeficiente de determinação de 0,492 entre os 0,53 acumulados nos dois primeiros eixos. Em relação às variáveis número de indivíduos, espécies e equabilidade, a DCA resultante parece refletir o 
Tabela 6 - Índices de similaridade de Jaccard (em negrito) e de Sørensen obtidos para a comunidade arbórea inventariada em três trechos na Serra Negra, Rio Preto, MG.

Table 6 - Jaccard (bold) and Sørensen Index between sampled areas.

\begin{tabular}{lccc}
\hline & Aluvial & Montana & Nebular \\
\hline Aluvial & - & 10,53 & 12,73 \\
Montana & $\mathbf{5 , 5 6}$ & - & 28,57 \\
Nebular & $\mathbf{6 , 8 0}$ & $\mathbf{1 6 , 6 7}$ & - \\
\hline
\end{tabular}

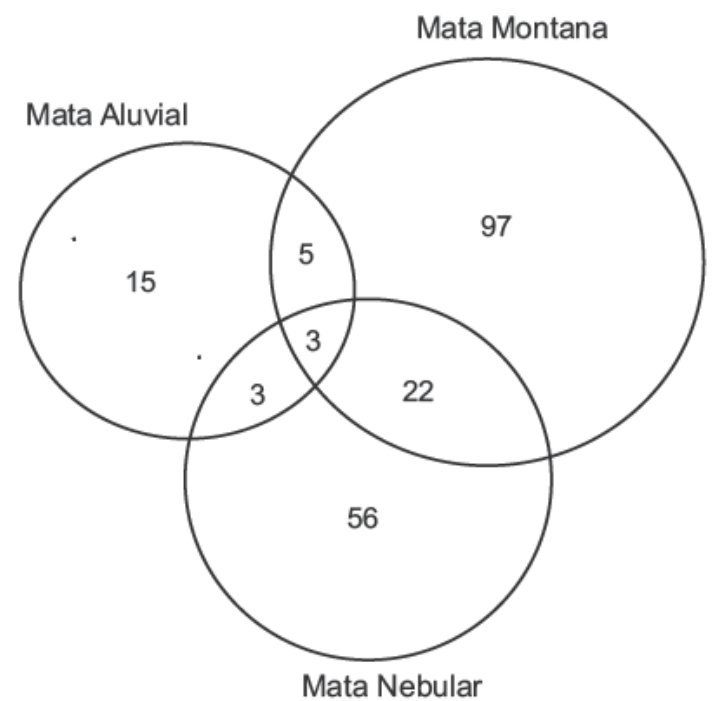

Figura 5 - Diagrama de Venn, mostrando o número de espécies arbóreas compartilhadas entre os três tipos florestais estudados na Serra Negra, Rio Preto, MG.

Figure 5-Venn diagram showing the number of tree species shared by the tree forest types sampled.

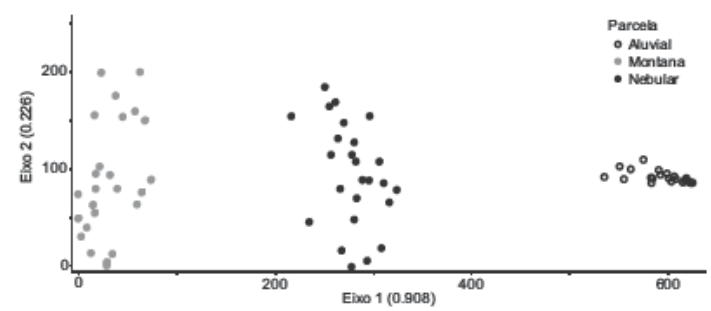

Figura 6 - Análise de Correspondência Destendenciada (DCA) envolvendo ocorrência e abundância de espécies arbóreas em três trechos florestais, na Serra Negra, Rio Preto, MG.

Figure 6 - Detrended Correspondence Analysis (DCA) matrix of species abundance in each plot sampled. gradiente do número de indivíduos e espécies no eixo 1, enquanto a equabilidade ou distribuição das abundâncias parece influenciar o segundo eixo.

A heterogeneidade florística da composição arbórea inventariada, quando comparada com demais levantamentos no complexo serrano da Mantiqueira e Zona da Mata mineira (Tab. 7), é evidenciada pela baixa similaridade florística. As maiores semelhanças em ordem decrescente de similaridade ocorreram com as áreas de Lima Duarte, seguida por Juiz de Fora, Ibitipoca, Aiuruoca, Bocaina de Minase Araponga 1 (Tab. 7). As menores similaridades ocorreram com as regiões da Mantiqueira Sul e Norte de altitudes muito elevadas como em Camanducaia, Monte Verde e Araponga 2.

A análise de agrupamento, primeiramente, reuniu duas áreas da Mantiqueira Sul inventariadas em altitudes acima de $1.800 \mathrm{~m}$, no município de Camanducaia (Fig. 7), na região sul de Minas Gerais. O segundo grupo reuniu os inventários realizados na Mantiqueira Norte, representados pelo Parque Estadual da Serra do Brigadeiro e seu entorno. O terceiro grupo formado reuniu os trabalhos realizados no maciço do Itatiaia e Ibitipoca. O quarto e último grupo reuniu os inventários da bacia do Paraíba do Sul na Zona da Mata mineira, Rio Preto, Lima Duarte e Juiz de Fora.

\section{Discussão}

A análise da composição, estrutura e similaridade florística do estrato arbóreo entre os três tipos de vegetação estudados na Serra Negra mostrou que, apesar da proximidade geográfica, os três tipos de vegetação são florística e estruturalmente distintos, o que configura alta diversidade beta para as florestas da região, com grande variação de ambientes pela altitude, posição topográfica e potenciais diferenças edáficas.

Considerando a riqueza arbórea estimada pelos índices Jacknife, a grandeza de 247 espécies para o conjunto dos três tipos de vegetação estudados, fortalece os argumentos para a conservação e reflete a riqueza da flora local, também verificada anteriormente no componente não arbóreo (Menini Neto et al. 2009). Cada tipo de vegetação estudado apresentou composição florística própria, suportada pelos baixos níveis de similaridade e pela DCA, além de se diferenciarem também quanto ao nível de diversidade. A maior diferença foi observada entre os índices de diversidade das matas aluviale montana, ainda que 
Tabela 7 - Índices de similaridade florística de Sørensen (Is) e Jaccard (Ij) entre a comunidade arbórea amostrada na Serra Negra, Rio Preto, MG, e outras áreas de floresta inventariadas em Minas Gerais, nas serras da Mantiqueira e Zona da Mata. NE = número de espécies; Tipo Veg = Tipo vegetacional; FN = Floresta Nebular; FS = Floresta Semidecídua; $\mathrm{FO}=$ Floresta Ombrófila.

Table 7 - Indices of floristic similarity of Sørensen (Is) and Jaccard (Ij) between the tree flora sampled in the Serra Negra, Rio Preto, MG, and other forest areas in Mantiqueira range and Zona da Mata. The sites are listed in descending order of Is. NE $=$ number of species; Veg type = vegetation type; FN = Cloud Forest, $\mathrm{SF}=$ Semi-deciduous Forest; FO = Rain Forest.

\begin{tabular}{llllccccc}
\hline Fonte & Sigla & \multicolumn{2}{c}{ Local de estudo } & Altitude & \multicolumn{2}{c}{$\mathbf{N E}$} \\
& & Área & $\begin{array}{c}\text { Tipo } \\
\text { Veg. }\end{array}$ & $\begin{array}{c}\text { média } \\
(\mathbf{m})\end{array}$ & $\begin{array}{c}\text { Total } \\
\text { spp. } \\
\text { comuns }\end{array}$ & Ij & Is \\
\hline Presente estudo & Funil & Rio Preto & FO & 1100 & 194 & - & - & - \\
Almeida 1996 & LimDua & Lima Duarte & FO & 1063 & 176 & 66 & 23,08 & 37,50 \\
Garcia 2007 & StaCanJF & Juiz de Fora & FS & 850 & 172 & 65 & 22,97 & 37,36 \\
Fontes 1997 & Ibit & Ibitipoca & FO & 1450 & 267 & 78 & 21,37 & 35,21 \\
Pereira et al. 2006 & Aiu & Aiuruoca & FO & 1095 & 207 & 66 & 20,82 & 34,46 \\
Pereira et al. 2006 & Bocaina & Bocaina de Minas & FO & 1300 & 156 & 51 & 18,15 & 30,72 \\
Soares et al. 2006 & entPESB & Araponga 1 & FS & 1200 & 110 & 43 & 17,7 & 30,07 \\
Ribeiro 2003 & PESB & Araponga 2 & FN & 1410 & 103 & 27 & 10,71 & 19,35 \\
Meireles et al. 2008 & MV & Monte Verde & FN & 1880 & 58 & 20 & 9,35 & 17,09 \\
França \& & Cam & Camanducaia & FN & 1900 & 48 & 15 & 7,18 & 13,39 \\
Stehmann 2004 & & & & & & & & \\
\hline
\end{tabular}

estas estejam mais próximas geograficamente entre si do que com a mata nebular. Muito provavelmente tal fato é decorrente das condições mais drásticas para recrutamento e estabelecimento de espécies arbóreas observadas na primeira, visto a periodicidade das inundações no sistema aluvial. A diversidade da mata montana foi superior à de florestas semidecíduas (Oliveira-Filho et al. 1994; Lopes et al. 2002) e similares a florestas bem conservadas da Serra da Mantiqueira (Meira-Neto et al. 1989; Saporetti Júnior 2005). A floresta aluvial estudada apresentou diversidade muito baixa, semelhante à de comunidades monodominantes (Nascimento \& Villela 2006; Silva et al . 2009).

Em matas paludosas, caracterizadas por substrato turfoso, a condição de encharcamento permanente do solo constitui-se no principal fator abiótico selecionando a ocorrência das espécies vegetais, o que resulta em diminuição da diversidade (Ivanauskas \& Rodrigues 2000). O tempo de encharcamento do solo influencia na seletividade dessas espécies em função de sua tolerância ao alagamento (Lobo \& Joly 2000).

Da característica fisionômica mais evidente da mata aluvial, dada pela alta frequência de perfilhamento e pela monodominância de Myrciaria tenella, observou-se interessante relação com as dez espécies seguintes de maior VI que apresentam altura superior à de $M$. tenella. Muito provavelmente essas espécies conseguiram o estabelecimento na comunidade aluvial não apenas por serem resistentes aos efeitos do alagamento, mas por levarem vantagem na competição por luz ao elevarem suas copas acima do denso dossel perenifólio. Entre as plantas com até $4 \mathrm{~m}$ de altura, a mata aluvial apresentou de metade a um terço da densidade de plantas observada na mata montana e na mata nebular, respectivamente (Fig. 4). O dossel denso e perenifólio de $M$. tenella parece contribuir para a manutenção da monodominância e dos baixos valores de diversidade e equabilidade e deve conferir alguma limitação ao estrato inferior, afetando a estrutura vertical da comunidade. Essa evidência é corroborada por Ivanauskas et al. (1997), que estudaram floresta decidual sob influência do alagamento no estado de São Paulo e verificaram que a equabilidade não foi afetada pela taxa de perfilhamento das espécies, mas a deciduidade talvez tenha influenciado positivamente o recrutamento das espécies, atenuando as relações de dominâcia.

Tanto o estresse pelo alagamento como a dominância de M. tenella parecem interferir negativamente na estrutura da comunidade arbórea, 


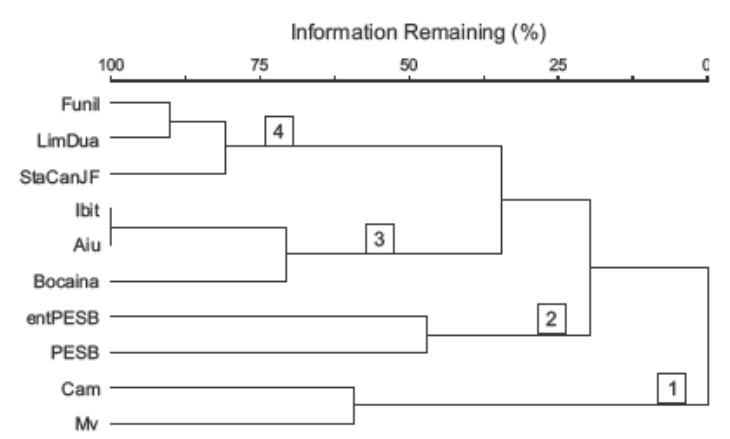

Figura 7 - Dendrograma de similaridade baseado em dados binários de 722 espécies arbóreas em 10 áreas de floresta atlântica nas serras da Mantiqueira e da Zona da Mata mineira. Com base na medida de distância de Sørensen e no método de agrupamento UPGMA. Siglas (vide Tabela 7).

Figure 7 -Similarity dendrogram, based on a binary matrix for 722 tree species from 10 atlantic forest regions in the Mantiqueira's range and Zona da Mata, MG. Based on the Sorensen distance measure and clustering method UPGMA. Acronymous (see Table 7).

que se caracterizou pelas menores médias de área basal e densidade de indivíduos vivos na mata aluvial. Assim, esses fatores podem promover o aumento de importância de poucas populações em matas ciliares como verificado neste estudo, ocasionar menor riqueza de espécies (Lieberman \& Lieberman 1987), além de alterar as interações bióticas (Lobo \& Joly 1995).

Ogradiente de altitude implicaem transformações das condições ambientais e influencia a distribuição de espécies arbóreas (Oliveira-filho \& Fontes 2000). Em florestas tropicais, à medida que ocorre a variação das cotas altimétricas, há a alteração nas características estruturais da comunidade florestal, com a diminuição no porte das árvores e o aumento da densidade em altitudes elevadas (Lieberman $e t$ al. 1996; Meireles et al. 2008). Também, ao longo de um gradiente altitudinal ocorrem modificações nas classes de solo, que tendem a se tornar mais rasos (Oliveira-Filho \& Fluminhan-Filho 1999). Contudo, o trecho amostrado na mata nebular está localizado no fundo de vale, onde é menos frequente a exposição da rocha e, consequentemente, os solos são mais profundos. Assim, a presença das espécies heliófitas e a maior profundidade dos solos ocasionaram a estratificação vertical mais complexa em relação ao esperado para florestas de altitude.

Entre as espécies mais abundantes do levantamento, Myrciaria tenella (519), Aparisthmium cordatum (94) e Alchornea triplinervia (259) ocorreram com maior VI nas matas aluvial, montana e nebular, respectivamente. Dessas, apenas A. triplinervia foi bem representada nas matas aluvial e nebular, o que provavelmente influenciou a proximidade destas áreas na DCA.

As variações das famílias com maior riqueza de espécies entre a mata montana e a mata nebular refletem os padrões encontrados no gradiente de altitude. Torres et al. (2004) observaram que espécies de Solanaceae (especialmente do gênero Solanum) ganham importância ao longo de um gradiente de altitude, enquanto espécies de Fabaceae tendem a desaparecer (Morim 2006). Myrtaceae e Lauraceae são características das florestas montanas neotropicais, geralmente bastante úmidas (Gentry 1995). Estes padrões florísticos decorrente do efeito da altitude foram congruentes com as diferenças observadas neste estudo entre as mata montana a 1.000 me nebular a $1.300 \mathrm{~m}$ de altitude, apresentando as famílias Myrtaceae e Lauraceae com maior riqueza, e a expressiva riqueza de Fabaceae observada a 1.000 m sendo substituída por espécies de Solanaceae e Melastomataceae a partir de $1.300 \mathrm{~m}$.

A altitude tem sido considerada como um gradiente complexo, dentro do qual muitos outros fatores ambientais variam e atuam em conjunto (Kent \& Coker 1992). Segundo Damasceno-Júnior (2005), as variações altitudinais trazem consigo alterações das condições ambientais que vão influenciar a distribuição e estrutura da vegetação e os padrões de riqueza das espécies. Os principais fatores envolvidos nas variações de distribuição de espécies ao longo dos gradientes altitudinais são: temperatura e umidade do ar, a forma de chuva ou de neblina, se intermitente ou permanente, ventose fatoresedáficos, como idade dos solos e disponibilidade de nutrientes.

A exposição de vertentes em cadeias de montanha pode ter um papel fundamental na definição de padrões de precipitação e temperatura e, por conseguinte, na distribuição de espécies de plantas. Porém, em escala local, os gradientes edáfico e altitudinal são mais perceptíveis (Pereira et al. 2006). Para Oliveira-Filho et al. (2005) as variações da altitude estão fortemente correlacionadas com a diferenciação interna tanto das florestas ombrófilas como das semideciduais.

$\mathrm{O}$ agrupamento dos dados florísticos obtidos por outros estudos em Ibitipoca, Aiuruoca e Bocaina indicaram, aparentemente, a maior proximidade dessas áreas com a Bacia do Rio Grande. Soares et al. (2006) demonstraram a relação de agrupamento de floras 
arbóreas em Minas Gerais refletidas em bacias hidrográficas e altitude. O subdomínio do Alto Rio Grande tem espécies em comum com a Mantiqueira Sul e que foram amostradas neste levantamento, entre elas, espécies características das fisionomias baixo e alto-montanas como: Capsicodendron dinisii, Kielmeyera coriacea, Alchornea sidifolia, Copaifera trapezifolia, Miconia tristis, Eugenia acutata e Ixora brevifolia. As espécies amostradas, comuns às fisionomias baixo e alto-montanas entre a Mantiqueira Norte e Sul, Vale do Paraíba do Sul e Alto Rio Grande foram: Aspidosperma australe, Schefflera calva, Persea wildenowii, Mollinedia triflora, Solanum pseudoquina e Laplacea fruticosa. Contudo, a presença de espécies de distribuição predominante na região do Vale do Paraíba do Sul promoveu o agrupamento da comunidade arbórea registrada na Serra Negra com levantamentos conduzidos em Juiz de Fora, Lima Duarte e Rio Preto. Ao analisar o conjunto florístico arbóreo do Vale do Paraíba do Sul, houve uma espécie amostrada em comum com a Mantiqueira Sul, Cryptocarya micrantha, e duas com a Mantiqueira Norte, Spirotheca rivieri e Miconia doriana. Entre as espécies amostradas em comum com o Vale do Paraíba do Sul e a Mantiqueira Norte e a Sul, características das fisionomias baixo e alto-montanas, encontram-se Ilex paraguariensis, Marliera laevigata, Solanum cinnamomeum e $S$. pseudoquina.

Entre as espécies amostradas, as que apresentaram distribuição entre as florestas baixomontana e alto-montana de Minas Gerais, citadas por Oliveira-Filho (2006) estão: Aspidosperma australe, Ilex paraguariensis, I. theezans, Schefflera calva, Capsicodendron dinisii, Kielmeyera coriacea, Alchornea sidifolia, Copaifera trapezifolia, Inga sessilis, Leucochloron incuriale, Persea wildenowii, Byrsonima myricifolia, Miconia doriana, Mollinedia triflora, Cybianthus peruvianus, Eugenia acutata, E. widgrenii, Macropeplus dentatus, Marlieria laevigata, Quiina glaziovii, Chomelia sevícia, Ixora brevifolia, Solanum cinnamomeum, S. pseudoquina, Daphnopsis coriacea e Drymis brasiliensis.

Apenas uma espécie, Eugenia widgrenii, é comum em floresta estacional semidecidual, enquanto as espécies mais representativas da floresta ombrófila foram: Quiina glaziovii, Byrsonima myricifolia, Eugenia melanogyna, Marlieria obscura, Ocotea lobbi, Spirotheca rivieri, Macropeplus dentatus e Tibouchina mutabilis.

Considerando apenas a distribuição das espécies em Minas Gerais, as espécies amostradas que se encontram predominantemente no Vale do Paraíba do Sul foram: Tabernaemontana laeta, Mimosa bimucronata, Miconia buddlejoides, Quiina magallano-gomesii e Qualea gestasiana.

As espécies características das formações baixo e alto-montanas e que ocorrem em toda a Serra da Mantiqueira em Minas Gerais, incluindo a Serra Negra, destacam-se Ilex theezans, Inga sessilis, Daphnopsis coriacea, Vochysia schwackeana, Cybianthus peruvianus, Drymis brasiliensis e Meriania clausenii, esta última unicamente encontrada nessa região. Entre as que se estendem mais comumente pela Mantiqueira Sul, destacamse Tibouchina mutabilis, Macropeplus dentatus, Myrcia palustris e Quiina glaziovii e, pela Mantiqueira Norte, ocorreram apenas Miconia tentaculifera e Coussarea verticillata.

Das espécies citadas acima como características de fitofisionomias da Mata Atlântica mineira, aquelas com distribuição exclusivamente pela Mata Atlântica e situadas somente na Região Sudeste foram: Eugenia widgrenii (Sobral et al. 2010), Macropeplus dentatus (Peixoto 2010), Quiina magallano-gomesii (Rocha \& Alves-Araújo 2010), Qualea gestasiana, Vochysia schwackeana (França 2010), Meriania claussenii (Chiavegatto et al. 2010), Tibouchina mutabilis (Guimarães 2010).

Entre os trechos analisados, as composições florísticas das matas montana e nebular evidenciaram as influências das tipologias floresta ombrófila baixo-montana e alto-montana, respectivamente (sensu Oliveira-Filho \& Fontes 2000). Na mata aluvial, devido ao encharcamento sazonal, verificou-se a tipologia floresta ombrófila aluvial. Desse modo, a composição arbórea na Serra Negra evidenciou predomínio de elementos ombrófilos, com penetrações na comunidade de espécies de florestas estacionais semidecíduas, o que contribui para alta riqueza de espécies. Observou-se ainda a ocorrência de espécies distribuídas predominantemente pelo Cerrado, como Kielmeyera coriacea, Terminalia triflora, Inga tenuis e Hirtella glandulosa. Outras espécies, comuns aos campos rupestres, também foram amostradas, como Myrcia guianensis, Laplacea fruticosa e Calyptranthes widgreniana.

O conjunto de espécies amostradas nas matas aluvial, montana e nebular e suas relações de similaridade com a flora arbórea de outros locais na Serra da Mantiqueira e Vale do Paraíba do Sul reforçam o argumento de que a vegetação florestal da Serra Negra é uma importante reserva de espécies arbóreas típicas da floresta atlântica. As florestas 
da região apresentam um conjunto considerável de elementos com distribuição característica de ambientes montanhosos do Sudeste do Brasil e, em uma escala mais detalhada, refletem as semelhanças entre os subdomínios Mantiqueira e Vale do Paraíba do Sul.

\section{Agradecimentos}

À Fundação de Amparo à Pesquisa do Estado de Minas Gerais (FAPEMIG) o suporte ao estudo da Flora da Serra Negra (Processo CRA 1891/06).

\section{Referências}

Ab'Saber, A.N. 2003. Os domínios de natureza no Brasil: potencialidades paisagísticas. 2 ed. Ateliê Editorial, São Paulo. 159p.

Almeida, V.C. 1996. Composição florística e estrutura do estrato arbóreo de uma floresta situada na Zona da Mata mineira, município, MG. Dissertação de Mestrado. Universidade Federal do Rio de Janeiro, Rio de Janeiro. 103p.

APG II. 2003. An update of the Angiosperm Phylogeny Group classification for the orders and families of flowering plants: APG II. Botanical Journal of the Linnean Society 141: 399-436.

Ayres, M.; Ayres Júnior. M.; Ayres, D.L. \& Santos, A.A.S. 2007. BioEstat: aplicações estatísticas nas áreas das ciências bio-médicas. Instituto de Desenvolvimento Sustentável Mamirauá, Belém. 364p.

Carvalho, D.A.; Oliveira-Filho, A.T.; Vilela, E.A.; Curi, N.; Berg, E.V.D.; Fontes, M.A.L. \& Botezelli, L. 2005. Distribuição de espécies arbóreo-arbustivas ao longo de um gradiente de solos e topografia em um trecho de floresta ripária do Rio São Francisco em Três Marias, MG, Brasil. Revista Brasileira de Botânica 28: 329-345.

Chiavegatto, B. 2010. Meriania. In: Lista de espécies da flora do Brasil. Jardim Botânico do Rio de Janeiro. Disponível em <http://floradobrasil.jbrj.gov.br/2010/ FB009652>. Acesso em dez 2010.

Costa, C. \& Herrmann, G. 2006. Plano de ação do corredor ecológico da Mantiqueira. Valor Natural, Belo Horizonte. 64p.

Dalanesi, P.E.; Oliveira-Filho, A.T. \& Fontes, M.A.L. 2004. Flora e estrutura do componente arbóreo da floresta do Parque Ecológico Quedas do Rio Bonito, Lavras, MG, e correlações entre a distribuição das espécies e variáveis ambientais. Acta Botanica Brasilica 18: 737-757.

Damasceno-Júnior, G.A. 2005. Estudo florístico e fitossociológico de um gradiente altitudinal no Maciço Urucum - Mato Grosso do Sul - Brasil. Tese de Doutorado. Universidade de Campinas, Campinas. 153p.

Drummond, G.M.; Martins, C.S.; Machado, A.B.M.; Sebaio, F.A. \& Antonini, Y. 2005. Biodiversidade em
Minas Gerais: um atlas para sua conservação. $2^{\mathrm{a}} \mathrm{ed}$. Fundação Biodiversitas, Belo Horizonte. 222p.

Durigan, G.; Rodrigues, R.R. \& Schiavini, I. 2000. A heterogeneidade ambiental definindo a metodologia de amostragem da floresta ciliar. In : Rodrigues, R.R. \& Leitão-Filho, H.F. (eds.). Matas ciliares: conservação e recuperação. EDUSP, São Paulo. Pp. 159-167.

Fontes, M.A. 1997. Análise da composição florística das florestas alto-montanas do Parque Estadual do Ibitipoca, Minas Gerais. Dissertação de Mestrado. Universidade Federal de Lavras, Lavras. 50p.

França, F. 2010. Vochysiaceae. In: Lista de espécies da flora do Brasil. Jardim Botânico do Rio de Janeiro. Disponível em <http://floradobrasil.jbrj.gov.br/2010/ FB015286>. Acesso em dez 2010.

França, G.S. \& Stehmann, J.R. 2004. Composição florística e estrutura do componente arbóreo de uma floresta altimontana no município de Camanducaia, Minas Gerais, Brasil. Revista Brasileira de Botânica 27: 19-30.

Garcia, P.O. 2007. Estrutura e composição do estrato arbóreo em diferentes trechos da Reserva Biológica Municipal de Santa Cândida, Juiz de Fora, MG. Dissertação de Mestrado. Universidade Federal de Juiz de Fora, Juiz de Fora. 91p.

Gentry, A.H. 1995. Patterns of diversity and floristic composition in neotropical montane forest. In: Churchill, S.P.; Baslev, H.; Forero, E. \& Luteyn, J.L. (eds.). Biodiversity and conservation of neotropical montane forest. The New York Botanical Garden Press, New York. Pp.103-126.

Guedes, R. R. 1998. Composição, estrutura e similaridade florística de dossel em seis unidades fisionômicas de Mata Atlântica no Rio de Janeiro. Tese de Doutorado. Universidade de São Paulo, São Paulo. $347 \mathrm{p}$.

Guimarães, P.J.F. 2010. Tibouchina. In: Lista de espécies da flora do Brasil. Jardim Botânico do Rio de Janeiro. Disponível em <http://floradobrasil.jbrj.gov.br/2010/ FB009944>. Acesso em dez 2010.

Humboldt, A. von. 1847. Cosmos - Essai d'une decription physique du monde. Guide et cie., Libraires Éditeur, Paris. 493p.

Ivanauskas, N.M. \& Rodrigues, R.R. 2000. Florística e fitossociologia de remanescentes de floresta estacional decidual em Piracicaba, São Paulo, Brasil. Revista Brasileira de Botânica 23: 291-304.

Ivanauskas, N.M.; Rodrigues, R.R. \& Nave, A.G. 1997. Aspectos ecológicos de um trecho de floresta em Itatinga, SP: florística, fitossociologia e seletividade de espécies. Revista Brasileira de Botânica 20: 139-153.

Kent, M. \& Coker, P. 1992. Vegetation description and analysis: a practical approach. Belhaven Press, London. 363p.

Lieberman, D. \& Lieberman, M. 1987. Forest tree growth and dynamics at La Selva , Costa Rica (1969-1982). Journal of Tropical Ecology 3: 347-358. 
Lieberman, D.; Lieberman, M.; Peralta, R. \& Hartshorn, G.S. 1996. Tropical forest structure and composition on a large-scale altitudinal gradient in Costa Rica. Journal of Ecology 84: 137-152.

Lobo, P.C. \& Joly, C.A. 1995. Mecanismos de tolerância à inundação de plantas de Talauma ovata St. Hil. (Magnoliaceae), uma espécie típica de matas de brejo. Revista Brasileira de Botânica 18: 177-183.

Lobo, P.C. \& Joly, C.A. 2000. Aspectos ecofisiológicos da vegetação de mata ciliar do Sudeste do Brasil In: Rodrigues, R.R. \& Leitão Filho, H.F. (eds.). Matas ciliares: conservação e recuperação. EDUSP, FAPESP, São Paulo. Pp. 143-141.

Lopes, W.D.; Silva, A.F.; Souza, A.L. \& Meira Neto, J.A. 2002. Estrutura fitossociólogica de um trecho de vegetação arbórea no Parque Estadual do Rio Doce - Minas Gerais, Brasil. Acta Botanica Brasilica 16: 443-456.

McCune, B. \& Mefford, M.J. 1999. PC-ORD version 4.0, multivariate analysis of ecological data. Users guide. MjM Software Design, Glaneden Beach. 148p.

Meira-Neto, J.A.A.; Bernacci, L.C.; Grombone, M.T.; Tamashiro, J.Y. \& Leitão-Filho, H.F. 1989. Composição florística da floresta semidecídua de altitude do Parque Municipal da Grota Funda (Atibaia, estado de São Paulo). Acta Botanica Brasilica 3: 51-74.

Meira-Neto, J.A.A. 2006. Diversidade e riqueza de espécies da flora da Mata Atlântica. In: Congresso Mineiro de Biodiversidade, Belo Horizonte. 6p.

Meireles, L.D.; Shepherd, G.J. \& Kinoshita, L.S. 2008. Variações na composição florística e na estrutura fitossociológica de uma floresta ombrófila densa altomontana na Serra da Mantiqueira, Monte Verde, MG. Revista Brasileira de Botânica 31: 559-574.

Menini Neto, L.; Matozinhos, C.N.; Abreu, N.L.; Valente, A.S.M.; Antunes, K.; Souza, F.S.; Viana, P.L. \& Salimena, F.R.G. 2009. Flora vascular nãoarbórea de uma floresta de grota na Serra da Mantiqueira, Zona da Mata de Minas Gerais, Brasil Biota Neotropica 9: 149-161.

Morim, M.P. 2006. Leguminosae arbustivas e arbóreas da Floresta Atlântica do Parque Nacional do Itatiaia, Sudeste do Brasil: padrões de distribuição. Rodriguésia 57: 27-45.

Mueller-Dombois, D. \& Elemberg, H. 1974. Aims and methods of vegetation ecology. Willey and Sons, New York. 547p.

Nascimento, M.T. \& Villela, D.M. 2006. Diversidade arbórea em florestas tropicais úmidas e o paradigma da monodominância. In: Mariath, J.E.A. \& Santos, R.P. (orgs.). Os avanços da botânica no início do século XXI: morfologia, fisiologia, taxonomia, ecologia e genética: Conferências Plenárias e Simpósios do $57^{\circ}$ Congresso Nacional de Botânica. Sociedade Botânica do Brasil, Porto Alegre. Pp. 373-377.

Oliveira-Filho, A.T.; Scolforo, J.R.S. \& Mello, J.M. 1994. Composição florística e estrutura comunitária de um remanescente de floresta semidecídua montana em Lavras, MG. Revista Brasileira de Botânica 17: 167-182.

Oliveira-Filho, A.T. \& Fluminhan-Filho, M. 1999. Ecologia da vegetação do Parque Florestal Quedas do Rio Bonito. Cerne 5: 50-63.

Oliveira-Filho, A. T. \& Fontes, M.A.L. 2000. Patterns of floristic differentiation among Atlantic Forests in Southeastern Brazil and the influence of climate. Biotropica 32: 793-810.

Oliveira-Filho, A.T.; Tameirão-Neto, E.; Carvalho, W.A.C.; Werneck, M.; Brina, A.E.; Vidal, C.V.; Resende, S.C. \& Pereira, J.A.A. 2005. Análise florística do compartimento arbóreo de áreas de floresta atlântica sensu latona região das bacias do leste (Bahia, Minas Gerais, Espírito Santo e Rio de Janeiro). Rodriguésia 56: 185-235.

Oliveira-Filho, A.T. 2006. Catálogo das árvores nativas de Minas Gerais: mapeamento e inventário da flora nativa e dos reflorestamentos de Minas Gerais. Ed. UFLA, Lavras. 423p.

Oliveira-Filho, A. 2009a. Classificação das fitofisionomias da América do Sul cisandina tropical e subtropical: proposta de um novo sistema - prático e flexível - ou uma injeção a mais de caos. Rodriguésia 60: 237-258.

Oliveira-Filho, A.T. 2009b. TreeAtlan 1.0, Flora arbórea da América do Sul cisandina tropical e subtropical: um banco de dados envolvendo biogeografia, diversidade e conservação. Universidade Federal de Minas Gerais. Disponível em <http://www.icb.ufmg.br/ treeatlan/>. Acesso em 2 dez 2009.

Paula, A.; Silva, A.F.; Júnior, P.M.; Santos, F.A.M.S. \& Souza, A.L. 2004. Sucessão ecológica da vegetação arbórea em uma floresta estacional semidecidual, Viçosa, MG, Brasil. Acta Botanica Brasílica 18: 407-423.

Peel, M.C.; Finlayson, B.L. \& McMahon T.A. 2007. Updated world map of the Köppen-Geiger climate classification. Hydrology and Earth System Sciences Discussions 4: 439-473.

Peixoto, A.L. 2010. Monimiaceae. In: Lista de espécies da flora do Brasil. Jardim Botânico do Rio de Janeiro. Disponível em <http://floradobrasil.jbrj.gov.br/2010/ FB010104>. Acesso em dez 2010.

Pendry, C.A. \& Proctor, J. 1996. The causes of altitudinal zonation of rain forests on Bukit Belalong, Brunei. Journal of Ecology 84: 407-418.

Pereira, I.M.; Oliveira-Filho, A.T.; Botelho, S.A.; Carvalho, W.A.C.; Fontes, M.A.L; Schiavini, I. \& Silva, A.F. 2006. Composição florística do compartimento arbóreo de cinco remanescentes do Maciço do Itatiaia, Minas Gerais e Rio de Janeiro. Rodriguésia 57: 103-126.

Pereira, J.A.A.; Oliveira-Filho, A.T. \& Lemos Filho, J.P. 2007. Environmental heterogeneity and disturbance by humans control much of tree species diversity 
of Atlantic montane forest fragments in SE Brazil. Biodiversity and Conservation 16: 1761-1784.

Ribeiro, C.A.N. 2003. Florística e fitossociologia de um trecho de floresta atlântica de altitude na Fazenda da Neblina, Parque Estadual da Serra do Brigadeiro, Minas Gerais. Dissertação de Mestrado. Universidade Federal de Viçosa, Viçosa. 61p.

Rocha, A.E.S. \& Alves-Araujo, A. 2010. Quiinaceae. In: Lista de espécies da flora do Brasil. Jardim Botânico do Rio de Janeiro. Disponível em <http:// floradobrasil.jbrj.gov.br/2010/FB078380>. Acesso em 1 dez 2010.

Rodrigues, R.R.. Morellato, L.P.C.; Joly, C.A. \& LeitãoFilho, H.F. 1989. Estudo florístico e fitossociológico em um gradiente altitudinal de mata estacional mesófila semidecídua, na Serra do Japi, Jundiaí, SP. Revista Brasileira de Botânica 12: 71-84.

Rodrigues, R.R. \& Leitão Filho, H.F. 2004. Matas ciliares: conservação e recuperação. $2^{\mathrm{a}}$ ed. EDUSP/FAPESP, São Paulo. 320p.

Sanchez, M. 2001. Composição florística e estrutura da comunidade arbórea num gradiente altitudinal da Mata Atlântica. Tese de Doutorado. UNICAMP, Campinas. 136p.

Saporetti Junior, A.W. 2005. Composição florística e estrutura do componente arbóreo em um remanescente de floresta atlântica montana, Araponga, MG. Dissertação de Mestrado. Universidade Federal de Viçosa, Viçosa. 84p.

Scolforo, J.R.S. \& Mello, J.M. 1997. Inventário florestal. UFLA/FAEPE, Lavras. 341p.

Scolforo, J.R.S. \& Carvalho, L.M.T. 2006. Mapeamento e inventário da flora nativa e dos reflorestamentos de Minas Gerais. Ed. UFLA, Lavras. 288p.

Shepherd, G.J. 1994. FITOPAC 1. Manual do usuário. UNICAMP, Campinas. 88p.

Silva, A.C.; van den Berg, E.; Higuchi, P.; Oliveira-Filho, A.T.; Marques, J.J.; Appolinário, V.; Pifano, D.S.; Ogusuku, L.M. \& Nunes, M. 2009. Florística e estrutura da comunidade arbórea em fragmentos de floresta aluvial em São Sebastião da Bela Vista, Minas Gerais, Brasil. Revista Brasileira de Botânica 32: 283-297.

Soares, M.; Saporetti Junior, A.W.; Meira Neto, J.A.; Silva, A.F. \& Souza, A.L. 2006. Composição florística do estrato arbóreo de floresta atlântica interiorana em Araponga-Minas Gerais. Revista Árvore 30: 859-870.

Sobral, M.; Proença, C.; Souza, M.; Mazine, F. \& Lucas, E. 2010. Myrtaceae. In: Lista de espécies da flora do Brasil. Jardim Botânico do Rio de Janeiro. Disponível em <http://floradobrasil.jbrj.gov.br/2010/ FB010568>. Acesso em dez 2010.

Souza, V.C. \& Lorenzi, H. 2005. Botânica sistemática: guia ilustrado para identificação das famílias de Angiospermas da flora brasileira, baseado na APG II. Instituto Plantarum, Nova Odessa. 640p.

ter Braak, C.J.F. 1995. Ordination. In: Jongman, R.H.G.; ter Braak, C.J.F. \& van Tongeren, O.F.R. (eds.). Data analysis in community and landscape ecology. Cambridge University Press, Cambridge. Pp. 91-173.

Torres, R.B.; Martins, F.R. \& Kinoshita, L.S. 1997. Climate, soils and tree flora relationship in forests in the state of São Paulo, southeastern Brazil. Revista Brasileira de Botânica 20: 41-49.

Valente, A.S.M. ; Garcia, P.O. ; Salimena, F.R.G. 2006. Zona da Mata mineira: aspectos fitogeográficos e conservacionistas. In: Oliveira, A.P.L. (org.). Arqueologia e patrimônio da Zona da Mata: Juiz de Fora. Vol. 2. Editar, Juiz de Fora. Pp. 71-91.

Veloso, H.P.; Rangel, A.L.R. \& Lima, J.C.A. 1991. Classificação da vegetação brasileira, adaptada a um sistema universal. IBGE, Rio de Janeiro. 124p.

W3 Tropicos. Disponível em <www.mobot.org >. Acesso em 1 dez 2010.

Whitmore, T.C. 1998. An introduction to tropical rain forests. $2^{\text {nd }}$ ed. Oxford University Press, Oxford. 296p.

Zar, J.H. 1996. Biostatistical analysis. Prentice Hall, New Jersey. 929p. 